\title{
Modulation Dynamics in the Orofacial Sensorimotor Cortex during Motor Skill Acquisition
}

\author{
Fritzie I. Arce-McShane, ${ }^{1}$ Nicholas G. Hatsopoulos, ${ }^{1,2}$ Jye-Chang Lee, ${ }^{3}$ Callum F. Ross, ${ }^{1}$ and Barry J. Sessle ${ }^{3}$ \\ ${ }^{1}$ Department of Organismal Biology and Anatomy, University of Chicago, Chicago, Illinois 60637, ${ }^{2}$ Committees on Computational Neuroscience and \\ Neurobiology, University of Chicago, Chicago, Illinois 60637, and ${ }^{3}$ Faculty of Dentistry, University of Toronto, Toronto, Ontario M5G 1G6, Canada
}

\begin{abstract}
The orofacial sensorimotor cortex is known to play a role in motor learning. However, how motor learning changes the dynamics of neuronal activity and whether these changes differ between orofacial primary motor (MIo) and somatosensory (SIo) cortices remain unknown. To address these questions, we used chronically implanted microelectrode arrays to track learning-induced changes in the activity of simultaneously recorded neurons in MIo and SIo as two naive monkeys (Macaca mulatta) were trained in a novel tongueprotrusion task. Over a period of $8-12 \mathrm{~d}$, the monkeys showed behavioral improvements in task performance that were accompanied by rapid and long-lasting changes in neuronal responses in MIo and SIo occurring in parallel: (1) increases in the proportion of taskmodulated neurons, (2) increases in the mutual information between tongue-protrusive force and spiking activity, (3) reductions in the across-trial firing rate variability, and (4) transient increases in coherent firing of neuronal pairs. More importantly, the time-resolved mutual information in MIo and SIo exhibited temporal alignment. While showing parallel changes, MIo neurons exhibited a bimodal distribution of peak correlation lag times between spiking activity and force, whereas SIo neurons showed a unimodal distribution. Moreover, coherent activity between pairs of MIo neurons was higher and centered around force onset compared with pairwise coherence of SIo neurons. Overall, the results suggest that the neuroplasticity in MIo and SIo occurring in parallel serves as a substrate for linking sensation and movement during sensorimotor learning, whereas the differing dynamic organizations reflect specific ways to control movement parameters as learning progresses.
\end{abstract}

Key words: electrophysiology; information; learning; motor cortex; orofacial; somatosensory cortex

\section{Introduction}

The orofacial sensorimotor cortex is crucial for orofacial motor control (Lowe, 1980; Huang et al., 1989b; Murray and Sessle, 1992a; Lin et al., 1994; Yao et al., 2002; Hatanaka et al., 2005; Sessle, 2006; Arce et al., 2013). Specifically, the orofacial primary motor cortex (MIo) and somatosensory cortex (SIo) exhibit neuroplasticity related to acquisition of novel oromotor skills, intraoral manipulations, and pain (Murray et al., 1991; Lin et al., 1993; Svensson et al., 2003, 2006; Sessle et al., 2005, 2007; AviviArber et al., 2010, 2011; Arima et al., 2011). Its dysfunction has been implicated in many orofacial sensorimotor disorders affecting feeding and speech found in stroke and Parkinsonism. Clinically, targeting the orofacial sensorimotor cortex has therapeutic promise (Martin, 2009; Konaka et al., 2010; Ciucci et al., 2011; Fleming et al., 2012; Mistry et al., 2012; Murdoch et al., 2012;

\footnotetext{
Received Oct. 11, 2013; revised Feb. 19, 2014; accepted March 21, 2014.

Author contributions: F.I.A.-M., N.G.H., C.F.R., and B.J.S. designed research; F.I.A.-M. and J.-C.L. performed research; N.G.H., J.-C.L., C.F.R., and B.J.S. contributed unpublished reagents/analytic tools; F.I.A.-M. and N.G.H. analyzed data; F.I.A.-M. wrote the paper.

This work was supported by Canadian Institutes of Health Research Grant MOP-4918. We thank Kazutaka Takahashi, Jose Iriarte-Diaz, Josh Coles, Kevin Brown, and Kate Murray for assistance with the experiments and Adam Dickey for help with the stability analysis.

The authors declare no competing financial interests.

Correspondence should be addressed to Dr. Barry J Sessle, Faculty of Dentistry, University of Toronto, 124 Edward Street, Toronto, Ontario M5G 166, Canada. E-mail: Barry.Sessle@dentistry.utoronto.ca.

DOI:10.1523/JNEUROSCI.4367-13.2014

Copyright $\odot 2014$ the authors $\quad 0270-6474 / 14 / 345985-13 \$ 15.00 / 0$
}

Nuckolls et al., 2012). However, because the dynamics of neuronal organization in the orofacial sensorimotor cortex during learning are poorly understood, so is the potential role of cortical therapies.

The current literature is conflicted as to the motor cortex's involvement in short-term and long-term learning (Kleim et al., 2004; Arima et al., 2011; Richardson et al., 2012), and the role of the somatosensory cortex at different stages of learning is poorly understood. Moreover, it remains unknown how learninginduced changes differ between the motor and sensory cortices in general and between MIo and SIo in particular. Recently, we have demonstrated that both MIo and SIo were highly involved in representing the direction of tongue protrusion but differed in the amplitude and temporal processing of the directional information (Arce et al., 2013). Thus, elucidating the time course of learning-induced changes in MIo and SIo, their combined contribution to the task, and their possible differences are important for addressing the potential of cortical therapies for disorders of the orofacial sensorimotor system.

The aim of this study was to evaluate changes affecting neuronal activity occurring simultaneously in MIo and SIo as naive monkeys learn a novel tongue-protrusion task over a period of $8-12 \mathrm{~d}$. Whereas previous adaptation studies have looked into one or a combination of rate modulation, variability, mutual information (MuI), and correlation (Paz and Vaadia, 2004; Kilavik et al., 2009; Song et al., 2013), here we used time-resolved 

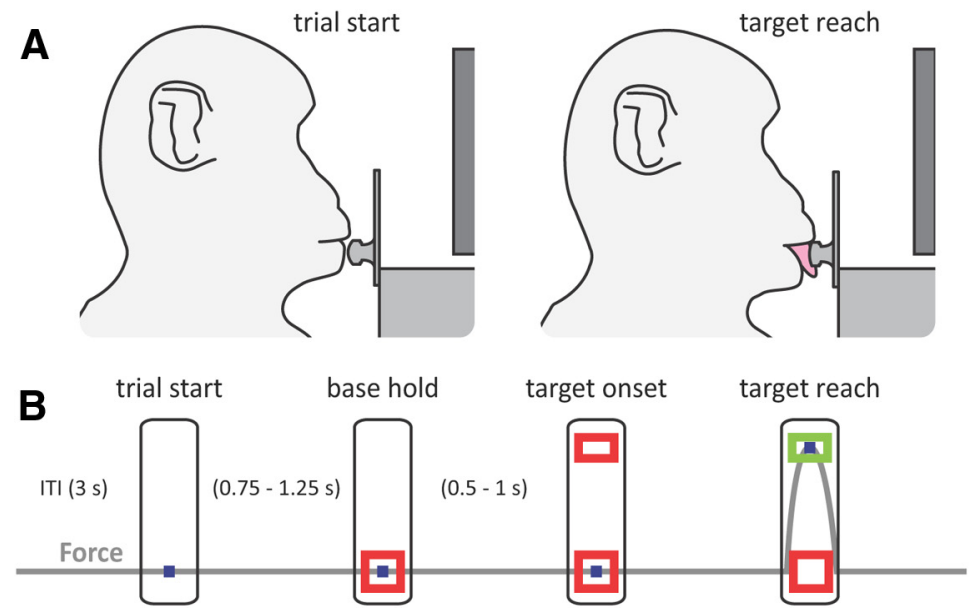

C

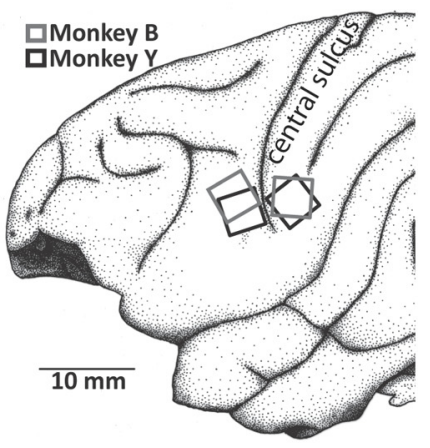

Figure 1. Experimental setup. $\boldsymbol{A}$, Monkey position relative to the transducer and monitor. $\boldsymbol{B}$, Diagram of the sequence of events in a trial of the tongue-protrusion task. Blue square represents the cursor. Colored boxes represent the base and force targets. A plot of the amplitude of tongue-protrusive force associated with the cursor displacement is superimposed for illustration (gray line). $\boldsymbol{C}$, Location of Mlo and Slo arrays of Monkey Y and Monkey B. Adapted from Arce et al., 2013.

MuI, pairwise coherence, and across-trial firing variability on neuronal populations to document the specific dynamics of neuronal organization during learning. We found that the improvements in the monkeys' behavioral performance were accompanied by neuronal changes occurring in parallel in MIo and SIo over short (within minutes) and long (over days) time-scales. Specifically, changes in the firing rate and across-trial firing variability in SIo were immediately apparent as in MIo, and the profiles of the information content in the activity of MIo neurons and of SIo neurons exhibited temporal alignment. Differences in the way MIo and SIo neurons' spiking activity relates to the generation of tongue-protrusive force were also observed. MIo and SIo exhibited differing distributions of lag times of peak correlation between spiking and force. Last, although transient increases in pairwise coherence were apparent in both MIo and SIo, their coherent activity differed in magnitude and timing.

\section{Materials and Methods}

All protocols for animal care and experimentation were submitted to and approved by our Institutional Animal Care and Use Committee and complied with the National Institutes of Health Guide for the Care and Use of Laboratory Animals. All experiments were conducted at the University of Chicago. Before, during, and after experimentation, monkeys were assessed regularly and assiduously for general well-being.

Behavioral task. Over a period of 8-12 training days, two naive nonhuman male primates (Macaca mulatta: $10 \mathrm{~kg}$, Monkey B; $12 \mathrm{~kg}$, Monkey $\mathrm{Y})$ learned to protrude the tongue onto a strain gauge in front of the monkey's mouth and apply isometric force at the level cued by target positions (Fig. 1A). With the head fixed and the forearms restrained, the monkey sat in front of a computer screen that displayed the targets and the cursor, which represented the amplitude of tongue-protrusive force applied on the transducer (Fig. 1B). Two target windows were shown on the screen to indicate the required force range: base target window with minimal tongue-protrusive force required $(0-15 \mathrm{~g})$ and force target window with required tongue-protrusive force $(50$ or $80 \mathrm{~g})$. The size of the force target window allowed a variability of $\pm 30 \mathrm{~g}$ from the required force level. Figure $1 B$ describes the sequence of events in a trial. The details have been previously described (Arce et al., 2013). Briefly, the trial started with the appearance of the cursor after an intertrial interval (ITI) of $3 \mathrm{~s}$. The base target window appeared after a random period between 0.75 and $1.25 \mathrm{~s}$ after trial start to cue the monkey to keep the cursor within the base target window for a random hold period between 0.5 and $1 \mathrm{~s}$. Upon successful hold at the base target (i.e., the monkey did not move the cursor beyond the base target window), the force target window appeared on the screen to signal the monkey to move the cursor into the force target window. When the cursor had reached the force target within the allotted time ( $5 \mathrm{~s}$ ), the force target window changed color to indicate success and the monkeys immediately received a juice reward. The trial end was defined by a success or failure event, and ITI immediately followed, during which the screen was blanked until the appearance of the cursor at the start of the next trial.

The behavioral program was written using Spike2 software (Cambridge Electronic Design). Force transducer (Revere Transducers, Mode 462-D3-2-10P1R, Tustin) signals and the behavioral event logs and time stamps were recorded at $2 \mathrm{kHz}$ and stored using the Power 1401 data acquisition system (Cambridge Electronic Design). User-designed pulse signals were generated to mark behavioral events and were sent to the neural data acquisition systems for offline synchronization of time stamps across the different data acquisition systems.

Electrophysiology. Under general anesthesia, each monkey was chronically implanted with two silicon-based microelectrode arrays of 100 electrodes (BlackRock Microsystems) in the MIo and SIo cortices of the left hemisphere (Fig. 1C). The microelectrodes on the array were separated from their immediate neighbors by $400 \mu \mathrm{m}$, and their length was $1.0 \mathrm{~mm}$ for all implanted arrays, except for one array that was $1.5 \mathrm{~mm}$ in length (MIo of Monkey Y). Microelectrode tips were coated with iridium oxide. Implantation sites were verified based on surface landmarks and observed evoked responses from the tongue and fingers after monopolar surface stimulation of MIo $(50 \mathrm{~Hz}, 200 \mu$ s pulse duration, 2-5 mA) during the surgical procedure. SIo was defined as the region posterior to the central sulcus and below the tip of the intraparietal sulcus, and at the same longitudinal axis with MIo. During each recording session, signals were amplified (gain $5000 \times$ ), bandpass filtered $(0.25-7.5 \mathrm{kHz})$, and recorded digitally (14-bit, $30 \mathrm{kHz}$ ) from both arrays simultaneously using two Cerebus acquisition systems (BlackRock Microsystems). Spike waveforms that passed a user-defined threshold were stored and sorted offline by using Offline Sorter (Plexon). Data from array channels with no signal or with large amounts of $60 \mathrm{~Hz}$ line noise were excluded.

Data analysis. Of the total training days, we sampled $6 \mathrm{~d}$ from each monkey to perform all the analyses described below. The choice was made based on success rates that were comparable between the monkeys. We refer to the first day as "pre-training day" and the other $5 \mathrm{~d}$ as "analysis days" to distinguish them from the actual training days.

Behavioral analyses. Only successful trials (i.e., trials wherein the monkey was able to apply the required force within the allotted time) were used in all analyses. The successful trials from days 1-5 were as follows: Monkey $\mathrm{Y}=[323,287,352,420,300]$; and Monkey B $=[213,255,254$, $146,348]$. Onsets of force generation were marked when tongue force last exceeded a defined threshold of $1 \mathrm{~g}$ before reaching two-thirds of peak force (Arce et al., 2013). Movement time was calculated from the onset of force to reward. 
Table 1. Summary of neuronal database ${ }^{a}$

\begin{tabular}{llllllll}
\hline & Mlo & & & & Slo & & \\
\cline { 2 - 3 } & $\begin{array}{l}\text { Total } \\
\text { recorded }\end{array}$ & $\begin{array}{l}\text { Preparatory } \\
\text { epoch }\end{array}$ & $\begin{array}{l}\text { Movement } \\
\text { epoch }\end{array}$ & & $\begin{array}{l}\text { Total } \\
\text { recorded }\end{array}$ & $\begin{array}{l}\text { Preparatory } \\
\text { epoch }\end{array}$ & $\begin{array}{l}\text { Movement } \\
\text { epoch }\end{array}$ \\
\hline Monkey Y & 597 & $47 \%(279)$ & $77 \%(461)$ & & 628 & $38 \%(238)$ & $74 \%(463)$ \\
Monkey B & 392 & $61 \%(240)$ & $85 \%(332)$ & & 278 & $33 \%(93)$ & $67 \%(187)$ \\
Total & 989 & $52 \%(519)$ & $80 \%(793)$ & & 906 & $37 \%(331)$ & $72 \%(650)$ \\
\hline
\end{tabular}

${ }^{a}$ Total number of neurons recorded from Mlo and Slo across 6 training days (2nd and 5th columns). Proportion (\%) of Mlo and Slo neurons whose activity was modulated in the preparatory epoch (3rd and 6th columns) or movement epoch (4th and 7th columns). Shown for each monkey and as total for both monkeys. Numbers in parentheses correspond to the population size.

Neuronal analyses. We examined the proportion of neurons that remained stable from pre-training to analysis day 5 by using the average waveform and interspike interval (ISI) as criteria (Dickey et al., 2009). The stability test takes a neuron's waveform and ISIs from a reference day (i.e., pre-training day) and compares them with that neuron's waveform and ISIs from each subsequent day. Analysis day 5 corresponds to the 12th day of training for Monkey Y and eighth day for Monkey B.

We analyzed single-unit activity recorded from MIo and SIo (Table 1) related to 2 epochs during a trial: preparatory (500 ms after target onset) and movement (500 ms after force onset). Single units were deemed task-modulated when their firing rates during a hold period $(500 \mathrm{~ms}$ before target onset) differed significantly from firing rates during the preparatory or movement epoch (paired $t$ test, $p<0.01$ ). To evaluate the degree of task modulation of each recorded neuron, we calculated a modulation index for each trial as follows:

$$
\text { Modulation index }=\frac{r_{(B, t)}-r_{(A, t)}}{r_{(A, t)}}
$$

$r$ is the mean firing rate of a neuron during the hold period $(A)$ or during either the preparatory or movement epoch $(B)$ of trial $t$. To evaluate within-session effects on firing rates, we used the successful trials within a block of 50 trials. For the across-session effects, all successful trials during a session were used.

To examine the temporal relationship between spiking activity and force production, we measured the trial-by-trial cross-covariance between the tongue-protrusive force and the spiking activity of taskmodulated MIo and SIo neurons by using $50 \mathrm{~ms}$ time bins and across a range of lags ( -0.5 to $0.5 \mathrm{~s}$ ). For each neuron, we tested the significance of the peak correlation by using a shuffling method ( $p<0.05$ ); neural time bins were randomly shuffled for all trials before calculating the cross-covariance with the tongue force. This shuffling procedure was repeated 100 times to obtain a distribution of correlations at the peak correlation time to determine significance. Using only the significant peak correlations, we determined the lag time in which the peak occurred for each neuron. The distribution of lag times when correlation peaked was fitted using a mixture of Gaussians model and an expectation-maximization clustering algorithm (Hastie et al., 2001).

We also quantified the amount of information available in the neuronal response by using information theoretic methods (MIToolbox) (Brown et al., 2012). Here we used MuI (Shannon, 1948) to quantify the reduction in uncertainty of the response of a single neuron $(X)$ given knowledge of the tongue-protrusion force $(Y)$. MuI was estimated as a reduction of the entropy of the observed spiking, $H(X)$, given the force amplitude, $H(X \mid Y)$ :

$$
\operatorname{MuI}(X, Y)=H(X)-H(X \mid Y) .
$$

$H(X)$ is the Shannon entropy defined for each neuron's spike count, $X$, measured in a $50 \mathrm{~ms}$ time bin as follows:

$$
H(X)=-\sum_{k=1}^{N} p_{k} \log _{2}\left(p_{k}\right),
$$

where $N$ is the maximum number of spike counts and $p_{k}$ is the probability of observing $k$ spikes in the bin. $H(X \mid Y)$ is the conditional entropy and defined as follows:
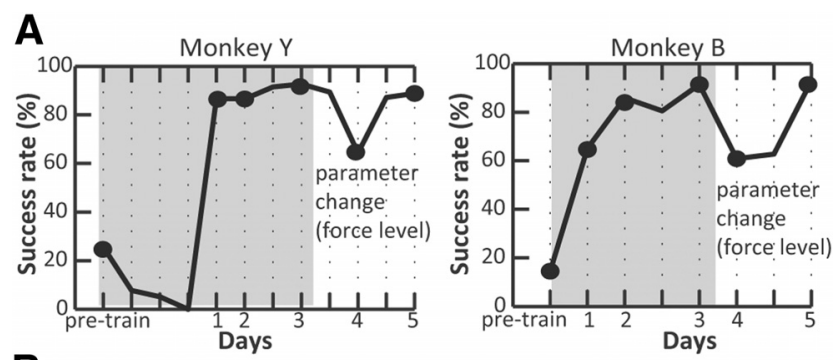

B
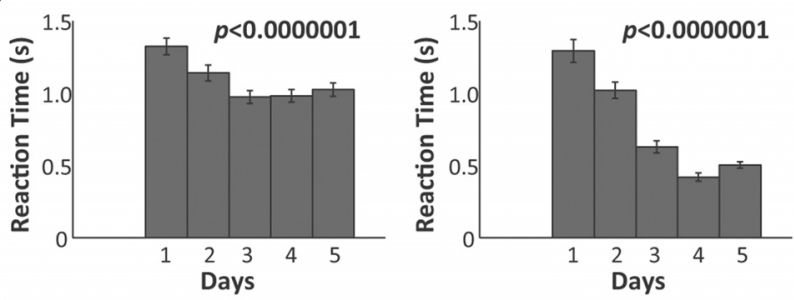

\section{C}
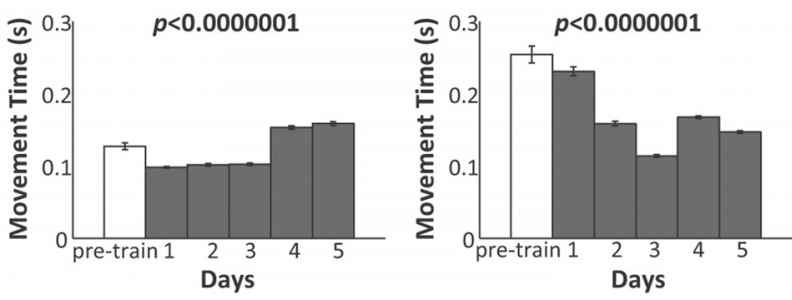

Figure 2. Behavioral changes with practice. $\boldsymbol{A}$, Success rates. Dots indicate the $6 \mathrm{~d}$ that were analyzed. Required force level was $50 \mathrm{~g}$ from pre-train to analysis days $1-3$ and was increased to $80 \mathrm{~g}$ on analysis days 4 and 5. B, Reaction time shown as mean across all trials for each analysis day. Reaction times for pre-train were excluded because monkeys responded not to target onset but to juice reward delivered manually by the experimenter. C, Movement time shown as mean across all trials for each analysis day. Error bars indicate SE. $p$ values correspond to KruskalWallis test. All behavioral parameters are shown separately for each monkey.

$$
H(X \mid Y)=\sum_{y} p(y)\left[\sum_{x} p(x \mid y) \log _{2} p(x \mid y)\right] .
$$

Marginal and conditional probabilities were estimated empirically. Because estimates of $\mathrm{MuI}$ are sensitive to the number of trials, we fixed the number of trials to be evaluated and used the first and last 50 trials of each day. This allowed for comparisons of MuI within a daily session and across different days. To account for biases in the estimation, we estimated the MuI by randomly shuffling the force bins associated with each trial (100 shuffles) and subtracting the mean shuffled estimates from the MuI obtained from the actual data.

Trial-by-trial variability of neuronal activity was analyzed using the Fano factor. To calculate the Fano factor, we used the ratio of the variance of the spike counts to their mean for the within-session analysis. For the across-sessions analysis, we used the mean matched Fano factor described previously (Churchland et al., 2010). Briefly, the method measures across-trial firing-rate variability in a way that controls for changes in firing rates to ensure that changes in the Fano factor are not the result of changes in the underlying firing rate. For this, two distributions are computed: the distribution of mean counts per time bin (i.e., the "actual distribution") and the distribution of mean counts for all time bins (i.e., the "greatest common distribution"). Mean matching is accomplished by discarding randomly chosen data points until the actual distribution matches the greatest common distribution, after which, the Fano factor (i.e., spike-count variance divided by spike-count mean) is calculated based on the remaining data points. The method also accounts for different trial sizes by using a weighted regression based on the estimated sampling error for the variance. For this analysis, we computed the Fano factor in a $50 \mathrm{~ms}$ sliding window moving in $10 \mathrm{~ms}$ steps for each neuron, and we used all trials from each practice session. 
Last, we evaluated the coherence between the spiking of neuronal pairs by using the multitapers method of the Chronux Toolbox (Mitra and Pesaran, 1999; Bokil et al., 2006). Spike-spike coherence, $C_{x y}$, is a frequencydomain representation of the cross-correlation of spike times between a pair of neurons calculated as the cross-spectra, $S_{x y}$, between the spike trains of neurons $x$ and $y$, normalized by the geometric mean of their autospectra, $S_{x x}$ and $S_{y y}$, respectively:

$$
C_{x y}=\frac{S_{x y}}{\sqrt{S_{x x} S_{y y}}},
$$

where $C_{x y}$ is a complex number whose modulus corresponds to the degree of coherence $(0-1)$ and the phase as the relative phase difference between the two spike trains at a particular frequency. We used a 500 ms sliding window with $10 \mathrm{~ms}$ steps and applied a smoothing window of $6 \mathrm{~Hz}$ and 5 orthogonal Slepian tapers to the data (first 50 or late 50 trials). We then applied a $K$-means clustering algorithm $(K=2)$ to distinguish those neuronal pairs that exhibited modulation of coherent activity to those that did not.

All statistical comparisons were made with nonparametric tests of differences between populations using MATLAB (MathWorks) with significance level set at $p<0.05$, unless otherwise noted.

\section{Results}

Over a period of $8-12 \mathrm{~d}$, the naive monkeys learned to protrude the tongue onto a strain gauge and apply isometric force at the level cued by target positions. On the pre-training day, the experimenter manually gave the monkeys the juice reward soon after the appearance of the force target to induce them to lick from the transducer. The monkeys were left on their own for the ensuing days of practice. Thus, the monkeys initially responded to the manual reward rather than to the target onset. In doing so, there was no reaction to the visual force target; thus, reaction time was not defined on the pre-training day. Nevertheless, the monkeys still needed to generate the required force to achieve success on a trial.

To track practice-related changes in the activity of neurons recorded from MIo and SIo in each monkey and in the monkey's performance of the tongue-protrusion task, we sampled one pretraining day and five training days from each monkey for the behavioral and the neuronal analyses (Fig. 2A, dotted days). We referred to the five training days as the analysis days.

\section{Behavioral findings}

On the pre-training day, the monkeys applied force on the transducer as they licked off the juice but without associating the target with achieving a required force level. As the monkeys were left on their own for the subsequent days, they learned to associate the target position to the tongue-protrusive force required to achieve reward. Indeed, both monkeys showed progressive increase in success rates with practice (Fig. $2 A$ ). When success rates stabilized $>80 \%$ for a few days, the task was made more difficult by increasing the required force level from 50 to $80 \mathrm{~g}$ on analysis day 4 . As a result, success rates went down but increased again to $>80 \%$ on analysis day 5 . With practice, reaction times also decreased from analysis day 1 to 5 (Fig. 2B; Kruskal-Wallis, $p<0.0000001$ ). Movement times significantly decreased from pre-training to analysis day 3 (Fig. 2C; Kruskal-Wallis, $p<0.0000001$, post hoc paired comparisons, $p<0.00001$ ), but movement duration increased again on analysis days 4 and 5 as the required force level to achieve success was increased.

\section{Neuronal findings}

Over the course of training, we recorded from $>600$ neuron samples in MIo and SIo of each monkey (Table 1). A neuron sample is a recording of a single unit on a given day and may represent the same neuron across multiple recording days. We then refer to this neuron as a stable unit. In MIo, we recorded an average of $99.5 \pm 2.3$ neurons per day for Monkey Y and $65.3 \pm$ 1.8 for Monkey B. In SIo, we recorded from $104.7 \pm 3$ neurons per day for Monkey Y and $46.3 \pm 2.9$ for Monkey B. Thus, on a given session, we recorded simultaneously at least 100 neurons from both MIo and SIo cortices in each monkey. The proportion of MIo and of SIo neurons that remained stable from pre-training day to analysis day 5 was $29 \%$ and $28 \%$, respectively (i.e., pooled for both monkeys; Fig. 3). When considering only the waveform score (Jackson and Fetz, 2007), the number of stable units increased to $43 \%$ in MIo and $30 \%$ in SIo. Because of the lower proportion of stable units found in Monkey B, all data analyses were performed on all task-modulated neurons of both monkeys.

\section{Modulation of neuronal activity to the tongue-protrusion task}

Figure $4 A, B$ illustrates the modulation of the spiking activity of four representative single neurons from MIo and SIo during tongue protrusion. Compared with the hold period ( $0.5 \mathrm{~s}$ before target onset), 52\% of the recorded MIo neurons exhibited significant modulation of their activity during the preparatory epoch ( $0.5 \mathrm{~s}$ after target onset) and $80 \%$ modulated their activity during the movement epoch ( $0.5 \mathrm{~s}$ after force onset) of the tongueprotrusion task (paired $t$ test, $p<0.01$ ). For SIo neurons, $37 \%$ were modulated during the preparatory epoch and $72 \%$ in the movement epoch (paired $t$ test, $p<0.01$ ). The proportion of task-modulated neurons was significantly higher in MIo than in SIo in both epochs for the pooled data across both monkeys (Table 1; binomial test, $p<0.00001$ ). This was also observed for each monkey separately for both epochs (binomial test, $p<$ 0.05), except for the movement epoch in Monkey Y where the proportions of MIo and SIo neurons were similar (binomial test, $p>0.10)$.

Simultaneous recording from many neurons during one session allowed us to define the activities of all neurons during the same behavioral session. The heat map illustrates the temporal dynamics in the normalized firing rates of the population of taskmodulated MIo and SIo neurons on analysis day 5 (Fig. 4C,D). Neurons were sorted in ascending order of time to peak firing, and high activity was depicted as red zones in the heat map. The high-activity zones, although widespread, appeared concentrated around force onset for many neurons. Likewise, the perievent 

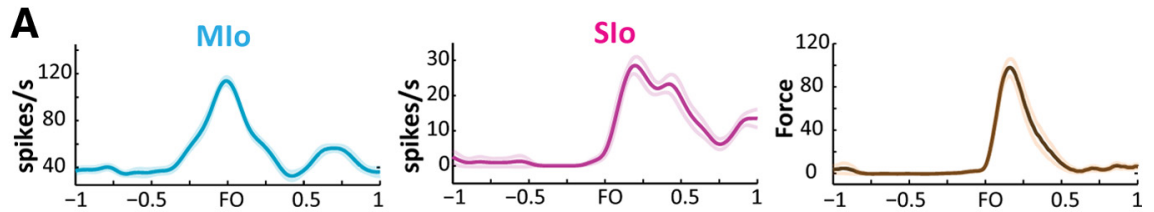

B
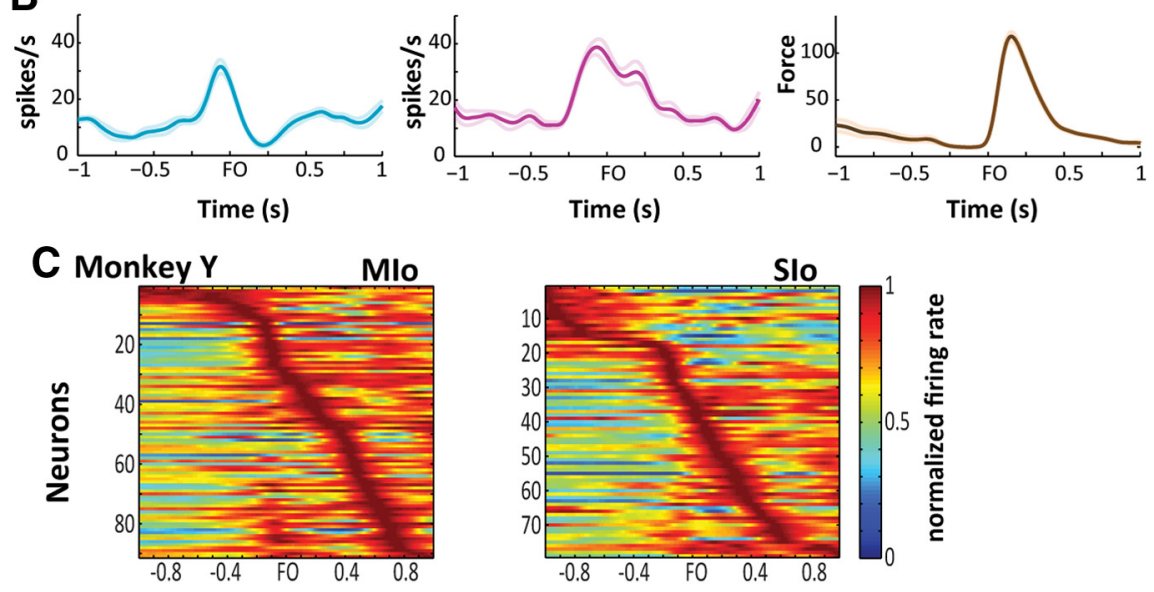

\section{Monkey B}
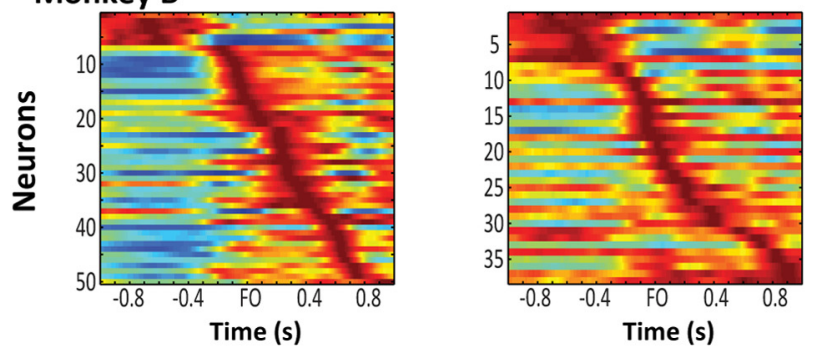

Figure 4. Modulation of neuronal activity to tongue-protrusion task. $A, B$, PETHs ( \pm SE), smoothed by a 50 ms Gaussian kernel of four simultaneously recorded Mlo and Slo neurons, respectively. PETHs are aligned to force onset (F0) and correspond to the first 20 trials. Mean \pm SE force profiles corresponding to the same trials used to plot the PETHs. C, D, Population activity in Mlo and Slo. Heat map depicting normalized firing rates $(0-1)$ of each task-modulated Mlo or Slo neuron ( $y$-axis) of Monkeys $Y$ and $B$, respectively. Each neuron's firing rates were normalized by the peak firing rate and aligned to $\mathrm{FO}$. Neurons were sorted according to the time of peak firing such that the first row corresponded to the neuron whose peak activity occurred at the earliest before force onset. Data correspond to analysis day 5.

time histograms (PETHs) suggest a strong correlation between the spiking activity and the tongue-protrusive force. We examined this further by correlating these two signals to determine how neural signals from MIo and SIo might lead or lag the generation of the tongue-protrusive force (see Materials and Methods). Cross-covariance between spiking activity and tongueprotrusive force is the cross-correlation of these two signals with their means removed. Here we normalized the cross-covariance to show correlation coefficients from -1 to 1 . Figure $5 A-C$ illustrates three examples of cross-covariance between force and spiking activity of a task-modulated neuron that we recorded across multiple days. Correlation coefficients were plotted at lags from -1 to $1 \mathrm{~s}$, with positive lags denoting the neuron's spiking activity leading the generation of force. MIo neuron 1 (Fig. 5A) showed peak correlation $\sim 0.2 \mathrm{~s}$, signifying that its activity led the generation of force. In contrast, spiking of MIo neuron 2 (Fig. 5B) lagged force as seen in the peak correlations occurring at negative lags. Activity of an example neuron in SIo lagged the generation of force by $0.3 \mathrm{~s}$ (Fig. 5C). The profile of the cross-covariance of these sample neurons remained stable across days with some changes in the magnitude and timing of peak cross-covariance. However, training days did not have an effect on the magnitude and timing of peak cross-covariance for the subpopulations of stable units in MIo and SIo across both monkeys (KruskalWallis, $p>0.10$ ). This was also true for the entire populations of task-modulated MIo and SIo neurons (Kruskal-Wallis, $p>0.10)$.

For the population analysis, we found that MIo neurons exhibited a bimodal distribution of lag times at which the correlation between the spiking activity and tongue-protrusive force peaked (Fig. 5D). The distribution of lag times of peak correlation were fit with a mixture model of Gaussians (Pearson's correlation, $r=$ 0.97 ) and was significant for a bimodal distribution (likelihood ratio test, $p<$ 0.0001 ); a subpopulation of MIo neurons led the generation of force by $223 \pm 113$ $\mathrm{ms}$ and the other subpopulation lagged the force by $167 \pm 119 \mathrm{~ms}$. In contrast, the population of SIo neurons showed a wide and unimodal distribution of lag times (Fig. $5 E$ ), with a mean lead time of $57 \pm$ $194 \mathrm{~ms}$. The above results were found to be consistent across both monkeys.

We then examined whether the two subpopulations of MIo neurons exhibited a spatial organization according to lag times for peak correlation. Monkey Y showed distinct spatial maps for the two subpopulations of MIo neurons; neurons that led the force were located more caudally close to the central sulcus than neurons that lagged the force (Fig. $5 F$ ). This was evident in the significantly higher proportion of MIo leading neurons compared with MIo lagging neurons located within the green-shaded area (binomial test, $p<0.001)$. This was also apparent in Monkey B, but to a lesser extent, possibly because of a different orientation of the array relative to the central sulcus (Fig. 5G). No pattern was noticeable for SIo neurons (data not shown).

\section{Practice effects on neuronal activity \\ Firing rate modulation}

Acquiring new skills may entail changes in the firing rates of neurons, which are already task-modulated and/or may be associated with neurons becoming modulated after acquisition of a new skill (Sessle et al., 2005, 2007; Arce et al., 2010a, b). Although success rates increased over days, monkeys showed fluctuating success rates during a given training day (Fig. 6A, $B$ ). Fluctuations within a session varied from day to day, and overall there was an upward trend in Monkey B's success rates from the start to the end of a session (Pearson's correlation, $r=0.27$ ), whereas a downward trend occurred in Monkey Y's success rates $(r=$ -0.44). Monkey Y's lower success rates in later trial blocks (i.e., after trial block 20) may be the result of fatigue; indeed, success rates did not have a trend when the success rates corresponding to the later trial blocks were not included in the correlation analysis. Because of the fluctuating success rates within a session, we evaluated the changes in neuronal activity over a short time-scale 
based on the success rates instead of comparisons between early and late trials. We assumed the effects of short-term learning would be maximal in trial blocks with high success rates.

Figure $6 C, D$ illustrates the fluctuations in a training session of Monkey Y. This is not a typical example but has been chosen to illustrate the fluctuations within a session. Success rates were plotted per trial block. Each trial block is a set of 50 successive trials and was incremented in 25 trial steps: trial block 1 corresponds to trials 1-50, trial block 2 corresponds to trials $26-75$, trial block 3 corresponds to trials $76-125$, etc. On average, a trial lasts $\sim 6 \mathrm{~s}$ (Fig. $1 B$ ) and a trial block (50 trials) can be completed within 5 min. Success rates in trial blocks 1-22 fluctuated between $50 \%$ and $70 \%$, then sharply dropped to reach a minimum of $4 \%$ at trial block 26 , and rose again to $60 \%$ in the last two trial blocks (Fig. $6 C, D$, blue line). Similar fluctuations were observed in the number of task-modulated neurons in both MIo and SIo (Fig. $6 C, D$, gold line) and their firing rate variability (Fig. $6 C, D$, purple line) during that same session. When success rates were high in a trial block, more neurons were engaged in the task, whereas when success rates were low in another trial block, fewer neurons were engaged. It should be emphasized that task modulation and firing rate variability were only computed on successful trials within each block. Figure $6 E, F$ summarizes this positive correlation between success rates and the proportion of taskmodulated MIo and SIo neurons during the preparatory epoch (Pearson's correlation, MIo: $r=0.33$, SIo: $r=0.41, p<$ 0.0001 ) and movement epoch (Pearson's correlation, MIo: $r=0.55$, SIo: $r=0.72$, $p<0.0001)$. Moreover, the firing rate variability of these task-modulated MIo and SIo neurons was positively correlated with success rates (Fig. $6 G, H$ ); the Fano factor of the preparatory epoch (Pearson's correlation, MIo: $r=0.41$, SIo: $r=0.29$ ) and movement epoch (Pearson's correlation, MIo: $r=0.52$, SIo: $r=0.30)$ significantly increased with success rates $(p<$ $0.0001)$. No correlations were found between success rates and the modulation indices of MIo or SIo neurons (Pearson's correlation, $p>0.10$ ), except for a significant negative correlation between success rates and modulation indices in MIo during the movement epoch (Pearson's correlation, MIo: $r=-0.45, p<0.0001$ ). These results indicate that dynamic changes in neuronal activity occurred within minutes of practice and were correlated with the monkey's successful performance on the task.

As monkeys became more successful in the tongue task across day sessions, we also found increasing proportions of MIo and of
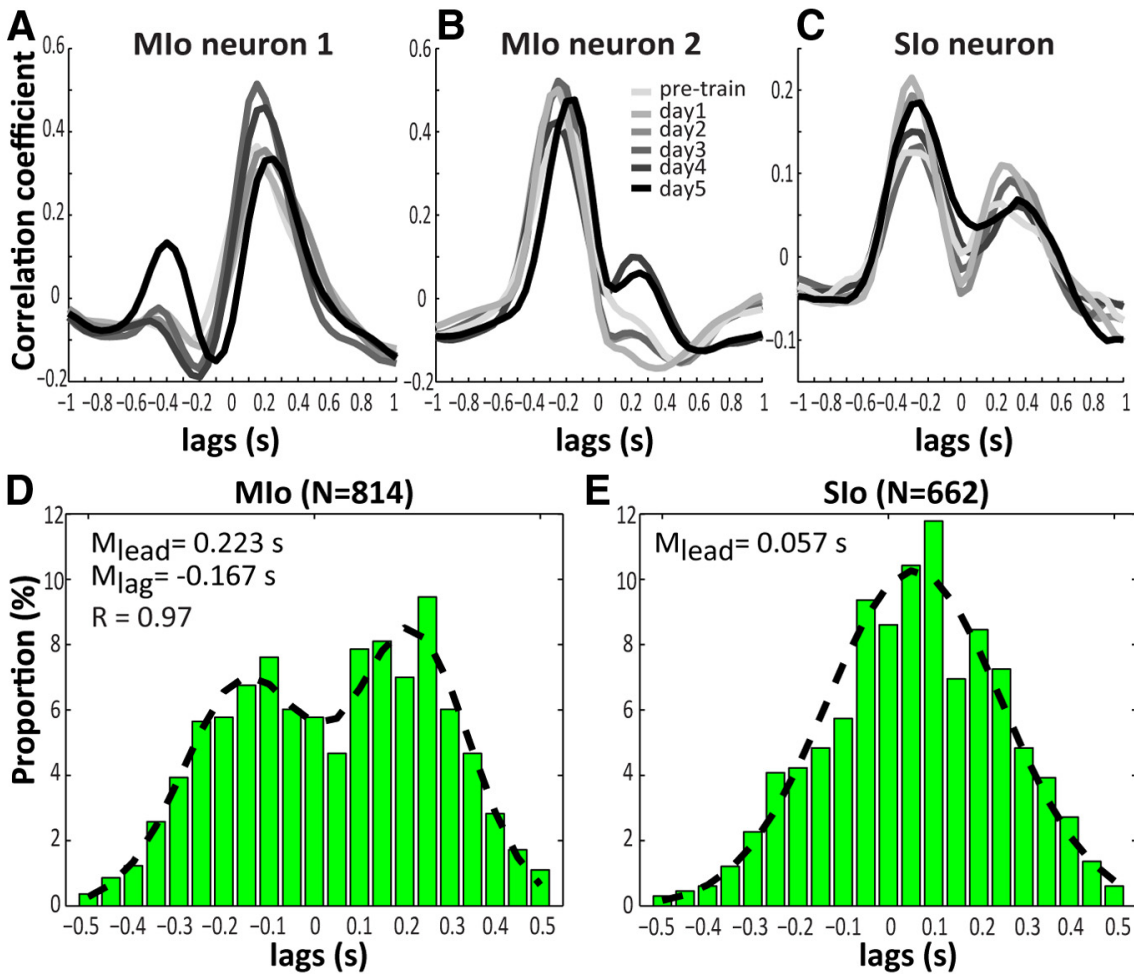

$\mathbf{E}$

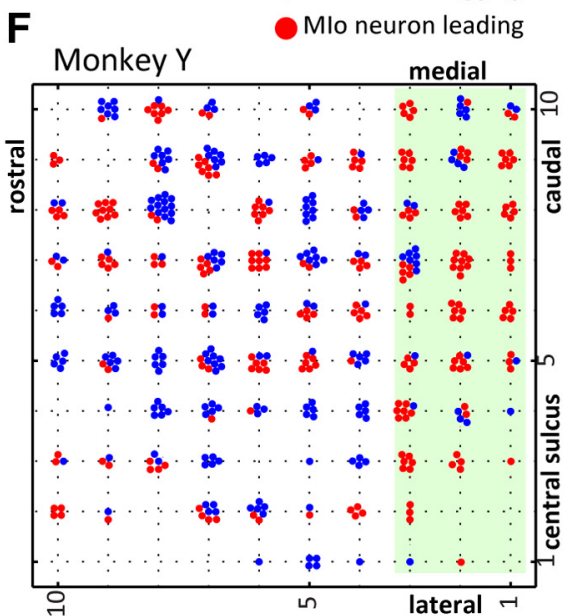

G

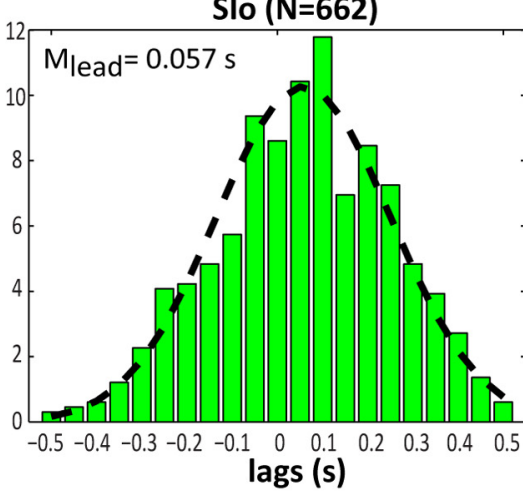
Monkey B medial

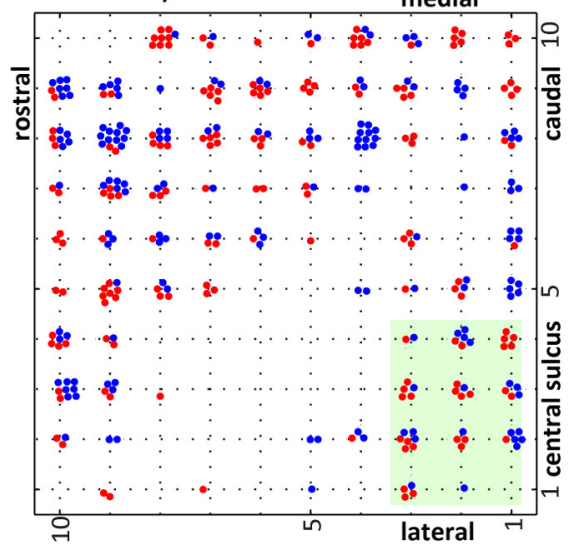

Figure 5. Cross-covariance functions between tongue-protrusive force and spiking activity of Mlo and Slo neurons. $\boldsymbol{A}-\boldsymbol{C}$, Cross-covariance shown for single neurons in Mlo and Slo across multiple days. Plots represent the correlation coefficients at specific lags. $\boldsymbol{D}, \boldsymbol{E}$, Distribution of lags when peak correlation between a neuron's spiking activity and tongue force occurred. Shown for Mlo and Slo, respectively. Positive lags correspond to neuron leading force. Distribution modes were characterized using a mixture of Gaussians model and an expectation-maximization clustering algorithm. Data pooled across monkeys. M, Mean; $R$, correlation coefficient between the actual data and the model of a mixture of Gaussians. $\boldsymbol{F}$, $\boldsymbol{G}$, Mapping of task-modulated Mlo neurons onto the electrode array. Each dot indicates a neuron with peak correlation at lags ranging from -0.5 to $0.5 \mathrm{~s}$. Shown for each monkey. The position of the array relative to the central sulcus was marked on the array's border. Shaded green area represents the area proximal to central sulcus.

SIo neurons that were modulated during the preparatory epoch (Fig. $7 A, B$ ). For SIo, the proportion of task-modulated neurons on analysis day 5 was significantly higher compared with analysis day 1 (Fig. $7 B$, gray dots; binomial test, $p<0.05$ ). For MIo, increasing proportions were also observed but reached significance only for comparisons between analysis days 1 and 4 (Fig. $7 A$, gray dots; binomial test, $p<0.05$ ). We excluded the results of the preparatory epoch of the pre-training day as monkeys did not actually prepare their movements in response to the target be- 

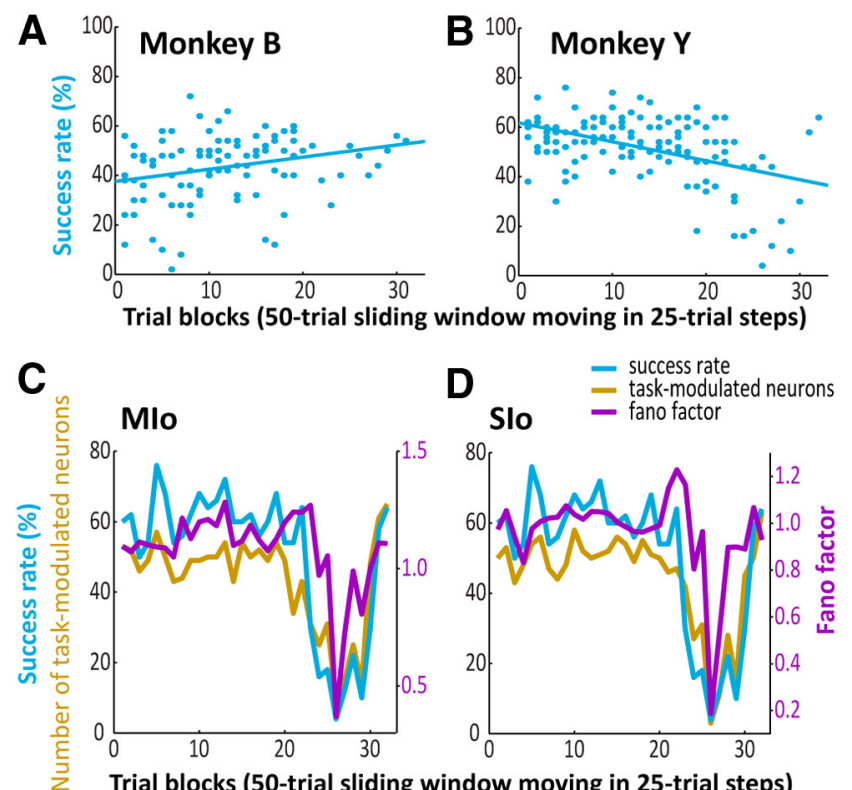

Trial blocks (50-trial sliding window moving in 25-trial steps)
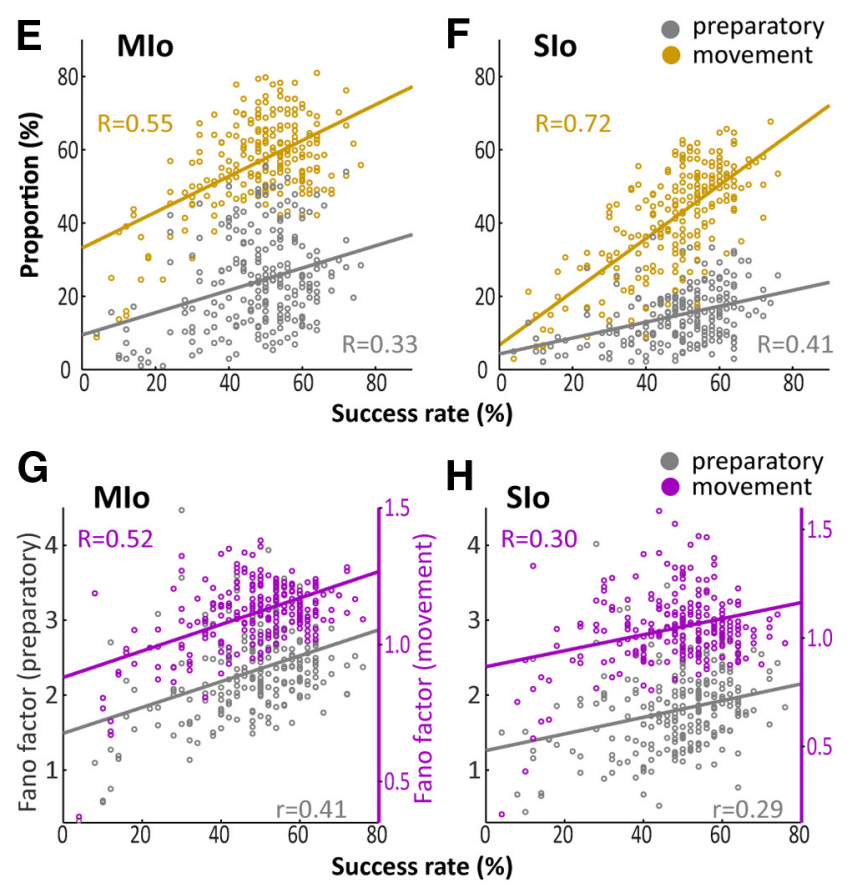

Figure 6. Short-term changes in the proportion of task-modulated neurons and firing rate variability. $\boldsymbol{A}, \boldsymbol{B}$, Success rates as a function of trial blocks (i.e., 50 trial sliding window moving in 25 trial steps) ordered from the beginning to the end of each training session. Shown separately for Monkeys B and Y. Lines correspond to a linear fit on the data. C, D, Success rates, Fano factor, and the number of modulated Mlo and Slo neurons in the movement epoch, respectively, plotted as a function of trial blocks. Shown for one dataset of Monkey Y. E, F, Correlation between success rates and the proportion of task-modulated Mlo and Slo neurons, respectively, during the preparatory and movement epochs. Shown as pooled data across the monkeys for all analysis days. $R$, Pearson's correlation coefficient. Lines correspond to a linear fit on the data. $\boldsymbol{G}$, $\boldsymbol{H}$, As in $\boldsymbol{E}, \boldsymbol{F}$, respectively, showing correlation between success rates and Fano factor. There are different scales used for the Fano factor corresponding to the preparatory and movement epochs.

cause they were induced on that day to protrude the tongue in response to the juice reward delivered manually after target onset. For the movement epoch, the proportions of MIo and of SIo neurons on analysis day 1 did not differ significantly from that of analysis day 5 (Fig. $7 A, B$, black dots; binomial test, $p>0.10$ ).
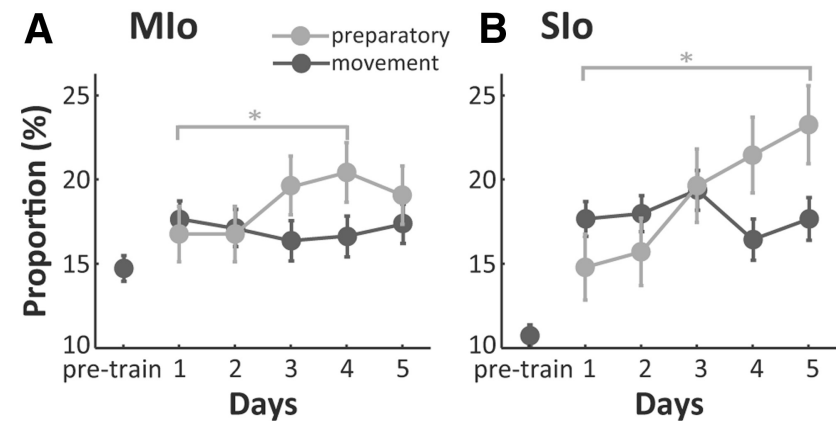

Figure 7. Changes in the proportion of task-modulated neurons with adaptation. $\boldsymbol{A}$, Sample proportion of Mlo neurons modulated during the preparatory and movement epochs across analysis days. Shown as pooled data across the monkeys. $\boldsymbol{B}$, As in $\boldsymbol{A}$ for Slo neurons. Error bars indicate SE. ${ }^{*} p<0.05$ (binomial test). The proportions corresponding to the preparatory epoch of pre-training day were excluded.

However, there was a noticeable increase in the proportion of MIo and SIo neurons from pre-training day to analysis day 1 . To evaluate the across-session effects on the modulation indices, we computed the mean modulation index across all trials for each neuron and compared the population means across days. There were no significant across-session effects on the mean modulation indices of MIo and SIo neurons in the preparatory or movement epoch of a trial (Kruskal-Wallis, $p>0.10$ ).

In sum, the pool of MIo and SIo neurons engaged in the task and their firing rate variability dynamically changed with the success rates within minutes. Across days, the pool of neurons engaged in the preparatory epoch became larger whereas the pool of neurons in the movement epoch remained unchanged. Within minutes, MIo neurons decreased their modulation during the movement epoch with increasing success rates. Over days, there were no changes in the modulation indices of MIo and SIo neurons in any of the trial epochs.

MuI increases with practice

Another possible consequence of motor skill acquisition is an increase in the information that neurons may carry in their spiking activity (Paz and Vaadia, 2004). We therefore quantified the changes in the information content in the spiking activity of each task-modulated neuron as monkeys learned to generate the tongue-protrusive force across sessions. Unlike in previous studies that measured MuI by using the entire trial time, here we measured a time-resolved MuI by taking the MuI in $50 \mathrm{~ms}$ time bins, from $1 \mathrm{~s}$ before force onset to $1 \mathrm{~s}$ after, to evaluate the temporal dynamics of the MuI. Figure $8 A-D$ illustrates the mean $\mathrm{MuI}$ estimated between the protrusive force and the spiking of task-modulated neurons recorded simultaneously from MIo and SIo from the end of each analysis day (i.e., last 50 trials). Figure $8 A, C$ (insets) depicts the MuI of a single neuron in MIo and in SIo, respectively. Both the $\mathrm{MuI}$ of a single neuron and the mean $\mathrm{MuI}$ across populations of neurons in MIo and SIo closely followed the profile of the tongue-protrusive force (Fig. $8 E, F$ ). More importantly, the mean MuI of MIo and SIo exhibited temporal alignment. Typically, very little information was available before force onset. Information content in the populations of task-modulated MIo and SIo neurons exhibited a significant rise coincident with the onset of tongue-protrusive force and decreased as the force returned to baseline. This was true for all the range of time lags tested ( -150 to $150 \mathrm{~ms}$ ). With practice across days, both monkeys exhibited a progressive increase in the information content; the mean MuI in MIo (Fig. $8 A, B$ ) and in SIo 
(Fig. 8C,D) on analysis day 5 from $0.1 \mathrm{~s}$ before force onset to $0.5 \mathrm{~s}$ after force onset were significantly higher than that of day 1 (Wilcoxon sign rank, MIo: $p<0.05$ for both monkeys; SIo: $p<0.001$ for both monkeys).

The progressive decrease in the reaction time as training progressed can be possibly mediated by the animal's increasing certainty with regards to the generation of the required force or increasing familiarity with the task. To evaluate this, we estimated the MuI between force and spiking activity aligned to the onset of the target. Figure $9 A-D$ shows increasing slopes of the rise in the information content with practice in both MIo and SIo. Moreover, MuI slopes for MIo correlated significantly with the mean reaction times (i.e., the slope of the MuI increased with decreasing reaction times) (Fig. 9E; Pearson correlation, MIo: $r=-0.71, p=$ 0.02). A similar correlation was found between the MuI slopes for SIo and the reaction times; however, it did not reach significance level (Fig. 9F; SIo: $r=-0.60$, $p=0.067)$.

Across-trial firing variability of the activity of task-modulated MIo and SIo neurons decreases with practice

How does the observed increase in the information content across sessions relate to changes in the response variability of task-modulated neurons when monkeys performed the tongue-protrusion task? To answer this question, we calculated a mean-matched Fano factor by using neuronal data aligned to target onset. Early in training, neuronal ensembles in both MIo and SIo exhibited greater variability during the reaction time (from target onset to $1 \mathrm{~s}$ after). This variability decreased during training on the task, indicating that the response of neurons became more reliable (Fig. 10; Kruskal-Wallis, $p<0.0000001$, post hoc Tukey-Kramer comparison between analysis day 1 and 5, $p<$ 0.01, except for SIo of Monkey Y). For MIo, both monkeys reached a comparable level of trial-by-trial variability in firing rates by analysis day 5 (Fig. 10A). However, the across-trial variability in SIo reached a significantly lower level in Monkey B than in Monkey Y (Fig. 10B; $p<0.001$ ).

As has been described for the limb motor cortex (MI) at the onset of reaching movements (Churchland et al., 2006), the across-trial variability in the firing rate of MIo neurons decreased as monkeys started to generate force. In MIo, the Fano factor corresponding to $0.5 \mathrm{~s}$ before force onset was significantly higher than the Fano factor corresponding to $0.5 \mathrm{~s}$ after force onset (Wilcoxon sign rank, $p<0.05$ for all MIo dataset of Monkey Y and for 3 MIo dataset of Monkey B). This was also observed in SIo (Wilcoxon sign rank, $p<0.05$ for all datasets). Moreover, a prominent difference in the across-trial variability between MIo and SIo was apparent; SIo consistently exhibited significantly

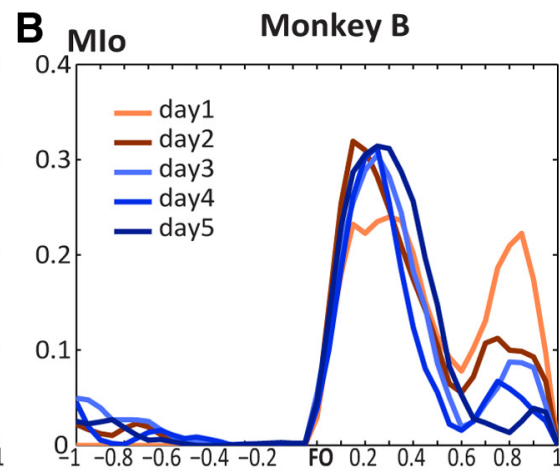

D slo

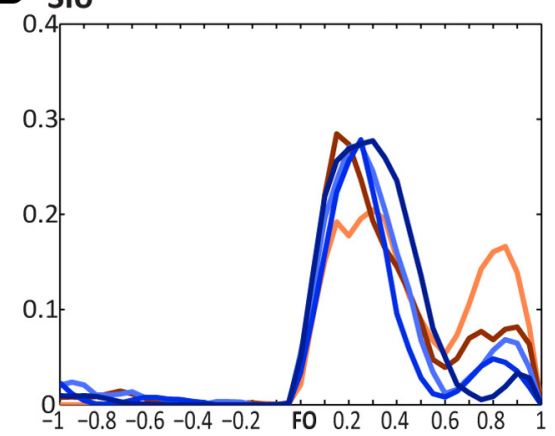

$\mathbf{F}$

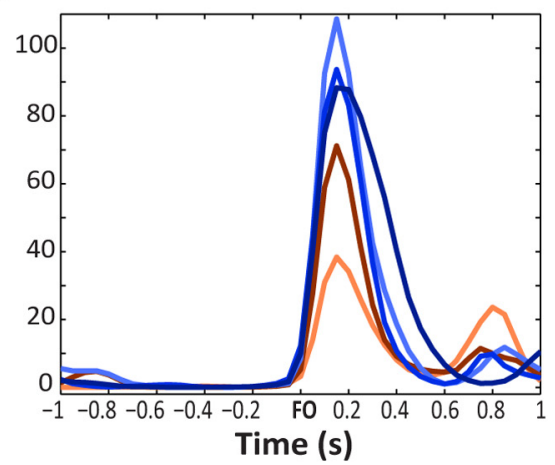

Time (s)

Figure 8. Mul between the tongue-protrusive force and spiking activity of task-modulated neurons in Mlo and Slo. $\boldsymbol{A}, \boldsymbol{B}$, Mean Slo neurons. Mul of a single Slo neuron shown in $\boldsymbol{C}$ (inset). $\boldsymbol{E}, \boldsymbol{F}$, Tongue-protrusive force from $1 \mathrm{~s}$ before F0 to $1 \mathrm{~s}$ after. Shown as mean across the last 50 trials of each analysis day.

higher variability than MIo across all datasets for Monkey Y (Wilcoxon sign rank, $p<0.001$ ) and across the first 4 analysis days for Monkey B (Wilcoxon sign rank, $p<0.001$ ).

\section{Modulation of coherent activity between neurons}

To test the hypothesis that motor learning induces coherent firing of neurons, we calculated the coherence between spiking activity of pairs of task-modulated neurons in MIo and SIo. Neuronal pairs in MIo and in SIo showed modulation of coherent activity for frequencies between 2 and $6 \mathrm{~Hz}$ (Fig. $11 A, B$ ). No modulation of coherent activity was found in other frequencies. The coherent activity between a pair of MIo or of SIo neurons typically increased before and around force onset. Although this was true for all the neuronal pairs that showed modulation of coherent activity (Fig. 11C,D), both the magnitude of coherence and the distributions of time to peak coherence in MIo and SIo differed. In MIo, the time to peak coherence was narrowly centered, occurring between -0.1 and $0.1 \mathrm{~s}$ relative to force onset in 

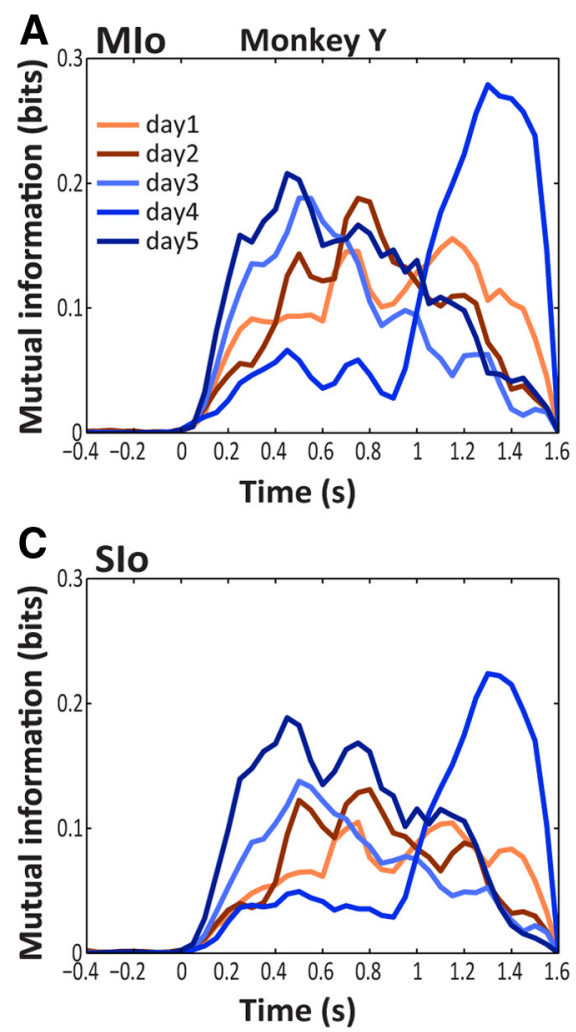
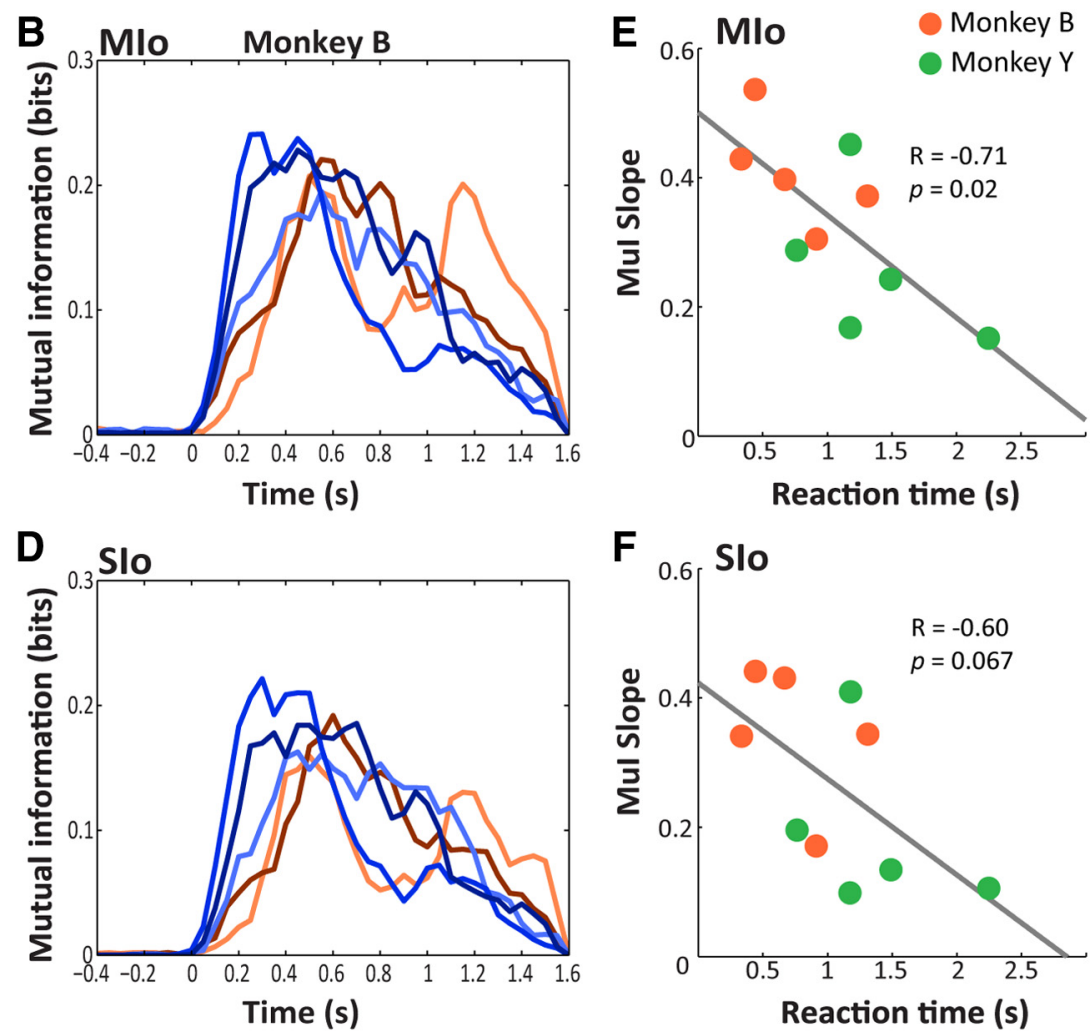

Figure 9. Mul and reaction times. $A, B$, Mean Mul between tongue-protrusive force and spiking activity of Mlo neurons aligned to target onset ( 0 s). Shown separately for each monkey. $C, D$, As in $\boldsymbol{A}, \boldsymbol{B}$, respectively, for Slo neurons. $\boldsymbol{E}, \boldsymbol{F}$, Correlation between reaction times and Mul slopes for Mlo and Slo, respectively. $p$ values correspond to $t$ test on the Pearson correlation. $R$, Correlation coefficient.

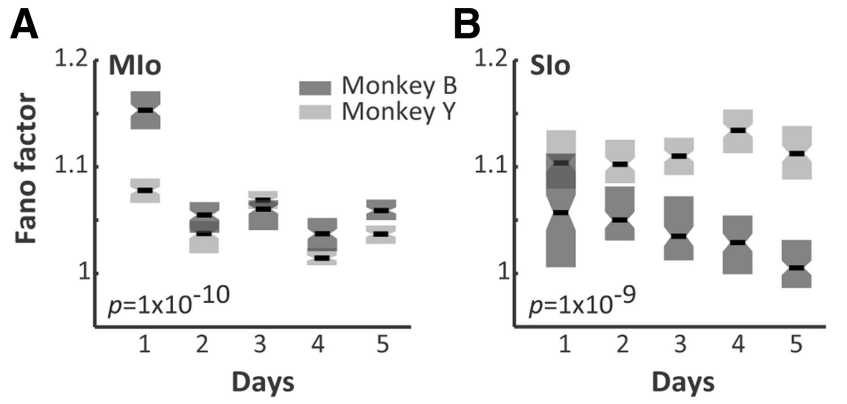

Figure 10. Mean-matched Fano factor for neuronal data aligned to target onset. $\boldsymbol{A}$, Daily Fano factor of Mlo neurons from each monkey separately. Shown as medians (central mark) from target onset to $1 \mathrm{~s}$ after target onset. Box edges correspond to the 25th and 75th percentiles. $p$ values correspond to Kruskal-Wallis test. $\boldsymbol{B}$, As in $\boldsymbol{A}$ for Slo neurons.

$54.44 \%$ of the neuronal pairs in contrast to $33.18 \%$ in SIo (pooled across all datasets and monkeys). The time to peak coherence in SIo ranged widely with the coherence of $63.53 \%$ of the neuronal pairs peaking between -0.1 and $0.3 \mathrm{~s}$ relative to force onset. Last, the magnitude of coherence in MIo was significantly higher than that of SIo (Mann-Whitney, $p<0.001$ ). These results were found consistently across all analysis days and monkeys.

The dynamic modulation within a trial showed graded changes from early to late trials of the same practice session; on day 1 , there was no distinct modulation of coherent spiking in a pair of MIo neurons and in a pair of SIo neurons on the first 50 trials, but this emerged in later trials (Wilcoxon sign rank, $p<$ 0.05, compare first 50 vs late 50 trials in Fig. $11 A$ for MIo and Fig. $11 B$ for SIo). Indeed, mean coherence across the populations of MIo and SIo neurons in both monkeys increased from early to late trials of analysis day 1 . Within-session effects on the mean coherence were significant for other analysis days for both monkeys (sign rank, $p<0.05$ for MIo analysis days 2-3 and for SIo analysis days $4-5$ ). Although the mean coherence across populations of MIo and SIo neuronal pairs did not differ significantly between early and late trials on some days as neuronal pairs either increased or decreased their coherent activity, an average of $69 \pm$ $1 \%$ of neuronal pairs in MIo and $68 \pm 2 \%$ in SIo showed significant within-session effects.

Coherence across the population of neuronal pairs in MIo and SIo also showed significant across-session learning effects. Figure $12 \mathrm{~A}$ illustrates the day-to-day changes in the pairwise coherence of a subset of MIo neurons recorded repeatedly from days 1-4 in Monkey Y. The coherent activity of neuron 58 with 5 other neurons (neurons 10, 22, 48, 62, and 64) located at varying distance from neuron 58 exhibited transient changes; coherence increased until it acquired a consistent temporal profile with a peak around force onset by day 3, then subsequently decreased. Although there were varying patterns of across-session changes in coherence (e.g., some neuronal pairs still showed substantial modulation of coherent activity on day 5), the pattern illustrated for the subset of neuronal pairs in Figure $12 A$ was observed for the mean coherence of the population of task-modulated neurons in MIo. Both monkeys showed a transient increase in coherence, peaking at mid-training (Fig. 12B; Kruskal-Wallis, $p<0.000001$, post hoc paired comparisons, $p<0.05$, days 1 vs 3 for Monkey Y; days 1 vs 2 for Monkey B), then decreasing in the subsequent days (post hoc paired comparisons, $p<0.001$, days 3 vs 4/5 for Monkey Y; days 2 vs 3-5 for Monkey B). For SIo, there was no observable pattern in the changes in the magnitude of the mean coherence over days (Fig. 12C). 

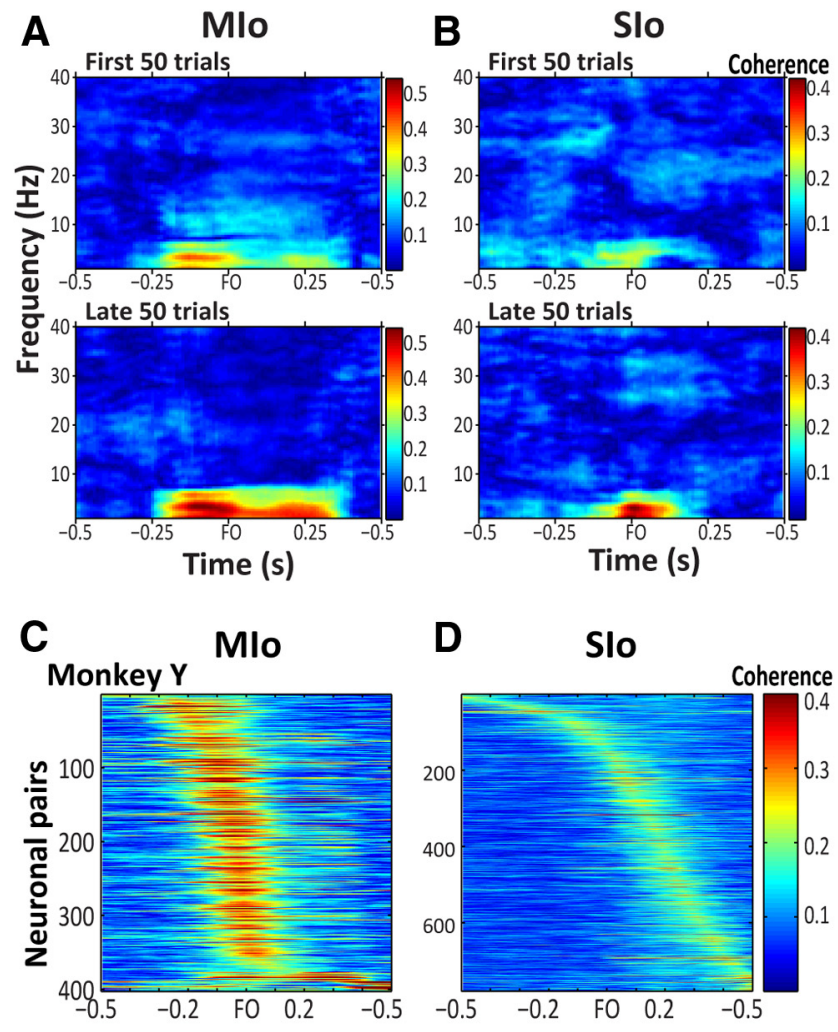

\section{Monkey B}
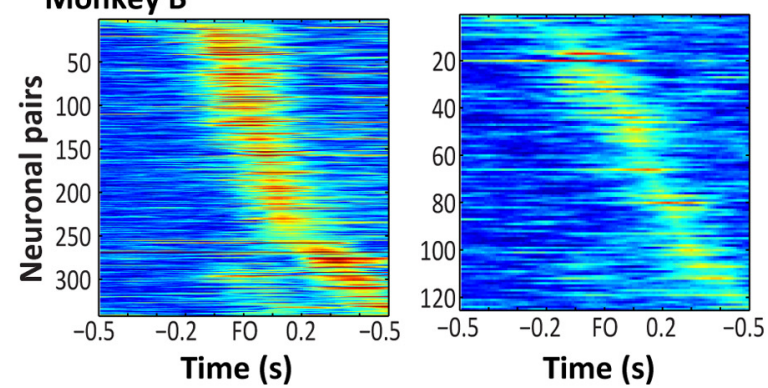

Figure 11. Spike-spike coherence. $A$, Example of coherent activity between a neuronal pair in Mlo during the first and late 50 trials. Shown from $0.5 \mathrm{~s}$ before force onset (F0) to $0.5 \mathrm{~s}$ after F0. $\boldsymbol{B}$, As in $\boldsymbol{A}$ for a neuronal pair in Slo. $\boldsymbol{C}, \boldsymbol{D}$, All neuronal pairs in Mlo and Slo that modulated their coherent activity during a session. Shown for each area and monkey. Each row represents the coherent activity of a neuronal pair from $0.5 \mathrm{~s}$ before $\mathrm{F} 0$ to $0.5 \mathrm{~s}$ after $\mathrm{FO}$. Color bar represents magnitude of coherence of a neuronal pair.

Last, we asked whether the coherence of neuronal pairs varied with the electrode distance between neurons, which would be indicative of common local synaptic inputs to the neuronal pair. We found that pairwise coherence in MIo and SIo did not vary with the location of the neurons in the electrode array (Pearson's correlation, $p>0.10$ ), consistent with previous findings in limb motor cortex (Maynard et al., 1999). This general finding is also illustrated in Figure 12A, showing that the coherence of neuron 58 with other neurons did not vary with interneuronal distance. The results suggest spatially broad functional connectivity (Juergens and Eckhorn, 1997).

\section{Discussion}

Our study compared day-to-day activities of simultaneously recorded neurons in the orofacial sensorimotor cortex as naive monkeys learned a novel tongue-protrusion task over 8-12 d. We have shown that learning-related neuroplastic changes in MIo and SIo occur in parallel, providing evidence for a mechanism underlying the linking of sensation and movement during sensorimotor learning. We also have shown differences in the dynamics of neuronal organization between MIo and SIo, further illuminating the specific functional roles served by each cortical area.

\section{Modulation of neuronal activity to the tongue-protrusion task}

An important finding of this study is that MIo and SIo neurons exhibited differing distributions of peak correlation lag times between tongue force and neuronal activity. MIo neurons were divided into two subpopulations: "lead" neurons that may drive force output (motor-related) and "lag" neurons that may report the force or the state of the orofacial muscles (sensory-related), which is consistent with MIo neurons exhibiting tongue mechanoreceptive fields (Murray and Sessle, 1992a; Arce et al., 2013). The peaks of the bimodal distribution may represent discrete time-points of activation: when motor commands were sent and when sensory-related information was received by MIo neurons, hence the bimodal distribution. In contrast, SIo neurons showed a unimodal and widespread distribution, indicating one population with varying temporal relations to force. SIo neurons may have a motor role in force generation. Indeed, SIo electrical stimulation can evoke tongue and jaw motor activity (Huang et al., 1989a; Hatanaka et al., 2005; Arce et al., 2013). Likewise, the preforce activity in SIo is analogous to the early directional information in SIo (Arce et al., 2013) or may reflect set-related activity from the premotor cortex (Yoshino et al., 2000; Grabski et al., 2012). Last, SIo has projections to MIo and brainstem motorneuron pools that may influence their engagement in the task (Huang et al., 1989a, b; Hatanaka et al., 2005; Avivi-Arber et al., 2011).

Our results are consistent with Murray and Sessle (1992b) and Lin et al. (1994) who also found neural onset times that led or lagged the force onset. The results of our cross-covariance analysis took these observations further by suggesting two distinct subpopulations of MIo neurons that relate to the encoding of force.

\section{Learning effects on behavior and neuronal activity}

The monkeys' task performance improved with learning as seen in the higher success rates, faster reaction times, and shorter movement durations over sessions. These performance improvements were mirrored by changes in the activity of MIo and SIo neurons across sessions. Within sessions, we also observed changes in neuronal activity associated with success rate, although they did not vary consistently with time over the session. Our study presented four ways in which neuronal activity changed during learning of a novel tongue-protrusion task: (1) rate modulation, (2) information content, (3) across-trial variability of spiking, and (4) coherent firing of neuronal pairs. Although these changes suggest neuroplasticity in MIo and SIo occurring over short and long time-scales, it is possible that neuroplasticity occurs in other areas and is only reflected in MIo and SIo, or that the changes could have been driven in part by factors, such as attention and motivation.

The spiking activity of neurons in limb MI has been shown to be modulated after adaptation to perturbed environment (Arce et al., 2010a, b; Richardson et al., 2012). Here, rate modulation was apparent as changes in the proportions of task-modulated neurons. Over a short time-scale, fluctuations in the daily behavioral performance correlated with the proportions of task- 

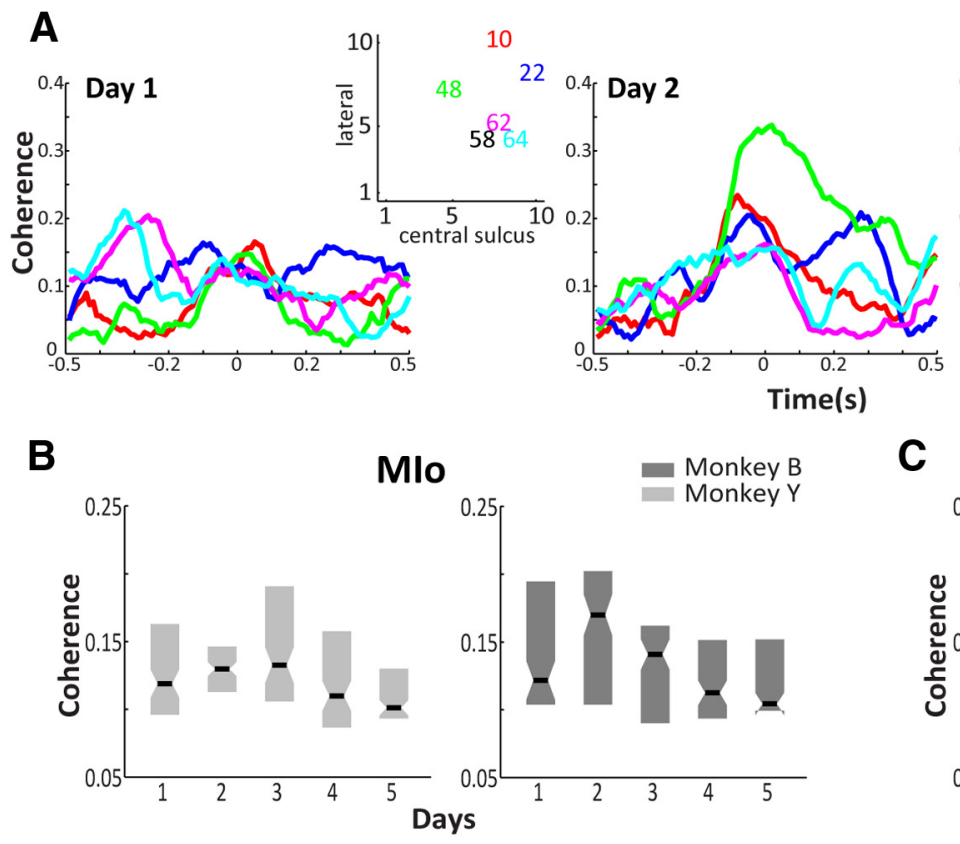
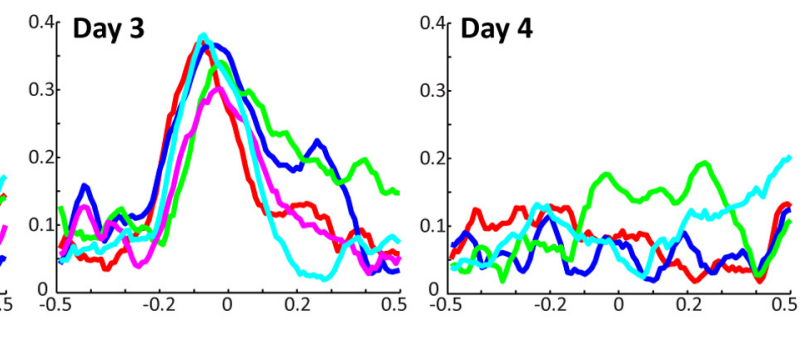

C

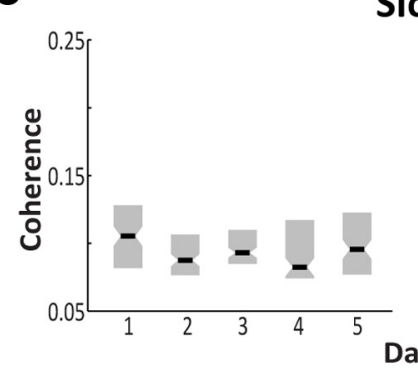

Slo

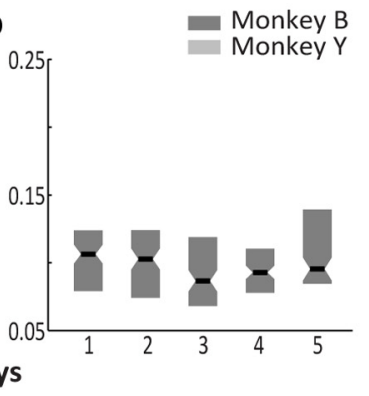

Figure 12. Transient changes in spike-spike coherence. $\boldsymbol{A}$, Pairwise coherence of a subset of stable Mlo neurons (5 pairs) across multiple days. Each line plot corresponds to a neuron paired with neuron 58. Inset, Position of the neurons (represented by ID numbers) on the $10 \times 10$ microelectrode array grid ( $4 \times 4 \mathrm{~mm})$. Data from Monkey Y. $\boldsymbol{B}$, Mean coherent activity of the population of neuronal pairs in Mlo during the late 50 trials of each analysis day, shown for Monkeys Y and B. C, As in B for the population of neuronal pairs in Slo shown for Monkeys Y and B. B, C, Kruskal-Wallis, $p<0.000001$.

modulated MIo and SIo neurons; the more neurons were engaged in the task, the higher the success rates. These rapid fluctuations in the pool size of task-related neurons are consistent with the increased tongue representation occurring within an hour of tongue-task training in humans (Svensson et al., 2006; Arima et al., 2011). We would argue that the nonmonotonic fluctuations in success rate within a session do not signify periods of learning and unlearning but reflect the engagement of a learning process that results in monotonic improvements over days. Over a longer time-scale, the pool of MIo and SIo neurons engaged during the preparatory epoch became larger, implying that monkeys developed anticipatory behavior as MIo and SIo neurons acquired new sensitivities after new or enhanced afferent inputs. Indeed, Sessle et al. $(2005,2007)$ reported increased number of SIo and MIo neurons showing tongue protrusion-related activity and lingual mechanosensory receptive fields after weeks of tongue-task training in monkeys. Similarly, in limb MI, sensory and motor representations increased after learning (Karni et al., 1995; Nudo et al., 1996). Our finding that the proportion of task-modulated neurons during the movement epoch did not increase is hard to explain but may result from the task not requiring complex movement strategies (Paz et al., 2003).

Improved information content after learning has been reported for motor (Paz and Vaadia, 2004) and sensory cortices (Adibi et al., 2013; Song et al., 2013). We also found increased information between the protrusive force and the spiking of MIo and SIo neurons, implying better encoding of force with practice. More importantly, the temporal evolution of the MuI across populations of MIo and SIo neurons matched that of the force profile, suggesting not only a parallel encoding by MIo and SIo, as found with directional information during tongue protrusion (Arce et al., 2013), but also a temporal alignment of sensory- and motor-related information between these areas (Salinas and Abbott, 1995; Huber et al., 2012). This provides evidence for a mechanism underlying the linking of sensation and movement during sensorimotor learning (Pavlides et al., 1993; Asanuma and Pavlides, 1997; Salinas and Romo, 1998). Such temporal alignment may serve as a substrate that allows for enhanced synaptic efficacy between MIo and SIo neurons as long-term potentiation depends critically on spike timing. Last, the correlation between the increasing MuI slopes in MIo and SIo and the decreasing reaction times of monkeys suggests that information content builds up faster with learning, thus allowing a more rapid response.

The faster information build-up following target onset and the overall increase in information were accompanied by improved reliability in the firing of the task-modulated MIo and SIo neurons. Early in training, neuronal ensembles in MIo and SIo exhibited greater fluctuations in firing rate, consistent with the exploratory behavior characterizing early skill acquisition. Such variability allows for variability in motor output necessary for motor learning (Song et al., 2000; Kao et al., 2005). Over days, this response variability was reduced. More reliable firing leads to a better readout by downstream neurons. Thus, both increased information and reliability allow for improved information processing and transmission for selecting the optimal movement strategies. Our other finding that firing rate variability increased with success rates within a session suggests that there were many successful movement strategies that map to many different spatiotemporal firing patterns, thus resulting in higher variability. On the other hand, trial blocks associated with low success rates used fewer and poor movement strategies that were similar to each other, thus resulting in low variability. Over the long term, the reduced variability suggests a streamlining of successful strategies for selecting the optimal strategy.

Synchronous firing is another way by which neurons convey information (Murthy and Fetz, 1992; Riehle et al., 1997; Hatsopoulos et al., 1998; Baker et al., 2001; Jackson et al., 2003; Sakamoto et al., 2008; Jia et al., 2013) and can be modulated by experience (Kilavik et al., 2009; Engelhard et al., 2013). As we 
hypothesized here, coherent activity between pairs of MIo and SIo neurons varied dynamically with learning. Our findings suggest that the coherent firing of neurons may effectively drive other neurons to fire (Abbott and Song, 1999; Fries, 2005), a neuroplastic mechanism that may underlie the formation of neuronal assemblies (Gerstein et al., 1989; Aertsen et al., 1991).

The coherent activity was dynamically modulated within-trial with the slow rhythms becoming highly coherent around force onset, consistent with findings in the limb MI (Hatsopoulos et al., 1998). Our finding that the coherent activity in MIo was significantly higher than that found in SIo implies an inherent need for synchronized firing in MIo for recruiting a large pool of motorneurons to generate force. In contrast, sensory information is received by SIo neurons at varying points relative to tongue protrusion and processed according to the activation sequence of SIo neuronal receptive fields. Such differences may also explain why coherent activity of neuronal pairs in MIo, but not in SIo, was concentrated around force onset.

The within-trial modulation of pairwise coherence showed graded changes across sessions and differed between MIo and SIo, suggesting that coherence changes as a function of the level of skill acquisition and the involved cortical area. In MIo, there was a transient increase in coherence within the first few training sessions followed by a subsequent decline, whereas coherence in SIo did not show any trend over days. The findings are consistent with early dendritic spine formation (within hours) in mouse motor cortex followed by spine elimination after $2 \mathrm{~d}$ of training (Xu et al., 2009; Yang et al., 2009; Komiyama et al., 2010).

\section{References}

Abbott LF, Song S (1999) Temporally asymmetric Hebbian learning, spike timing and neuronal response variability. In: Advances in neural information processing systems, Ed 11 (Kearns MS, Solla SA, Cohn DA, eds), Cambridge, MA: Massachusetts Institute of Technology.

Adibi M, McDonald JS, Clifford CW, Arabzadeh E (2013) Adaptation improves neural coding efficiency despite increasing correlations in variability. J Neurosci 33:2108-2120. CrossRef Medline

Aertsen A, Vaadia E, Abeles M, Ahissar E, Bergman H, Karmon B, Lavner Y, Margalit E, Nelken I, Rotter S (1991) Neural interactions in the frontal cortex of a behaving monkey: signs of dependence on stimulus context and behavioral state. J Hirnforsch 32:735-743. Medline

Arce FI, Lee JC, Ross CF, Sessle BJ, Hatsopoulos NG (2013) Directional information from neuronal ensembles in the primate orofacial sensorimotor cortex. J Neurophysiol 110:1357-1369. CrossRef Medline

Arce F, Novick I, Mandelblat-Cerf Y, Israel Z, Ghez C, Vaadia E (2010a) Combined adaptiveness of specific motor cortical ensembles underlies learning. J Neurosci 30:5415-5425. CrossRef Medline

Arce F, Novick I, Mandelblat-Cerf Y, Vaadia E (2010b) Neuronal correlates of memory formation in motor cortex after adaptation to force field. J Neurosci 30:9189-9198. CrossRef Medline

Arima T, Yanagi Y, Niddam DM, Ohata N, Arendt-Nielsen L, Minagi S, Sessle BJ, Svensson P (2011) Corticomotor plasticity induced by tongue-task training in humans: a longitudinal fMRI study. Exp Brain Res 212:199212. CrossRef Medline

Asanuma H, Pavlides C (1997) Neurobiological basis of motor learning in mammals. Neuroreport 8:i-vi. Medline

Avivi-Arber L, Lee JC, Sessle BJ (2010) Effects of incisor extraction on jaw and tongue motor representations within face sensorimotor cortex of adult rats. J Comp Neurol 518:1030-1045. CrossRef Medline

Avivi-Arber L, Martin R, Lee JC, Sessle BJ (2011) Face sensorimotor cortex and its neuroplasticity related to orofacial sensorimotor functions. Arch Oral Biol 56:1440-1465. CrossRef Medline

Baker SN, Spinks R, Jackson A, Lemon RN (2001) Synchronization in monkey motor cortex during a precision grip task: I. Task-dependent modulation in single-unit synchrony. J Neurophysiol 85:869-885. Medline

Bokil HS, Pesaran B, Andersen RA, Mitra PP (2006) A method for detection and classification of events in neural activity. IEEE Trans Biomed Eng 53:1678-1687. CrossRef Medline
Brown G, Pocock A, Zhao S, Lujan M (2012) Conditional likelihood maximisation: a unifying framework for information theoretic feature selection. J Machine Learning Res 13:27-66.

Churchland MM, Yu BM, Cunningham JP, Sugrue LP, Cohen MR, Corrado GS, Newsome WT, Clark AM, Hosseini P, Scott BB, Bradley DC, Smith MA, Kohn A, Movshon JA, Armstrong KM, Moore T, Chang SW, Snyder LH, Lisberger SG, Priebe NJ, et al. (2010) Stimulus onset quenches neural variability: a widespread cortical phenomenon. Nat Neurosci 13:369378. CrossRef Medline

Churchland MM, Yu BM, Ryu SI, Santhanam G, Shenoy KV (2006) Neural variability in premotor cortex provides a signature of motor preparation. J Neurosci 26:3697-3712. CrossRef Medline

Ciucci MR, Russell JA, Schaser AJ, Doll EJ, Vinney LM, Connor NP (2011) Tongue force and timing deficits in a rat model of Parkinson disease. Behav Brain Res 222:315-320. CrossRef Medline

Dickey AS, Suminski A, Amit Y, Hatsopoulos NG (2009) Single-unit stability using chronically implanted multielectrode arrays. J Neurophysiol 102:1331-1339. CrossRef Medline

Engelhard B, Ozeri N, Israel Z, Bergman H, Vaadia E (2013) Inducing gamma oscillations and precise spike synchrony by operant conditioning via brain-machine interface. Neuron 77:361-375. CrossRef Medline

Fleming SM, Schallert T, Ciucci MR (2012) Cranial and related sensorimotor impairments in rodent models of Parkinson's disease. Behav Brain Res 231:317-322. CrossRef Medline

Fries P (2005) A mechanism for cognitive dynamics: neuronal communication through neuronal coherence. Trends Cogn Sci 9:474-480. CrossRef Medline

Gerstein GL, Bedenbaugh P, Aertsen MH (1989) Neuronal assemblies. IEEE Trans Biomed Eng 36:4-14. CrossRef Medline

Grabski K, Lamalle L, Vilain C, Schwartz JL, Vallée N, Tropres I, Baciu M, Le Bas JF, Sato M (2012) Functional MRI assessment of orofacial articulators: neural correlates of lip, jaw, larynx, and tongue movements. Hum Brain Mapp 33:2306-2321. CrossRef Medline

Hastie T, Tibshirani R, Friedman JH (2001) The elements of statistical learning: data mining, inference, and prediction (with 200 full-color illustrations). New York: Springer.

Hatanaka N, Tokuno H, Nambu A, Inoue T, Takada M (2005) Input-output organization of jaw movement-related areas in monkey frontal cortex. J Comp Neurol 492:401-425. CrossRef Medline

Hatsopoulos NG, Ojakangas CL, Paninski L, Donoghue JP (1998) Information about movement direction obtained from synchronous activity of motor cortical neurons. Proc Natl Acad Sci U S A 95:15706-15711. CrossRef Medline

Huang CS, Hiraba H, Murray GM, Sessle BJ (1989a) Topographical distribution and functional properties of cortically induced rhythmical jaw movements in the monkey (Macaca fascicularis). J Neurophysiol 61:635650. Medline

Huang CS, Hiraba H, Sessle BJ (1989b) Input-output relationships of the primary face motor cortex in the monkey (Macaca fascicularis). J Neurophysiol 61:350-362. Medline

Huber D, Gutnisky DA, Peron S, O'Connor DH, Wiegert JS, Tian L, Oertner TG, Looger LL, Svoboda K (2012) Multiple dynamic representations in the motor cortex during sensorimotor learning. Nature 484:473-478. CrossRef Medline

Jackson A, Fetz EE (2007) Compact movable microwire array for long-term chronic unit recording in cerebral cortex of primates. J Neurophysiol 98:3109-3118. CrossRef Medline

Jackson A, Gee VJ, Baker SN, Lemon RN (2003) Synchrony between neurons with similar muscle fields in monkey motor cortex. Neuron 38:115125. CrossRef Medline

Jia X, Tanabe S, Kohn A (2013) $\gamma$ and the coordination of spiking activity in early visual cortex. Neuron 77:762-774. CrossRef Medline

Juergens E, Eckhorn R (1997) Parallel processing by a homogeneous group of coupled model neurons can enhance, reduce and generate signal correlations. Biol Cybern 76:217-227. CrossRef Medline

Kao MH, Doupe AJ, Brainard MS (2005) Contributions of an avian basal ganglia-forebrain circuit to real-time modulation of song. Nature 433: 638-643. CrossRef Medline

Karni A, Meyer G, Jezzard P, Adams MM, Turner R, Ungerleider LG (1995) Functional MRI evidence for adult motor cortex plasticity during motor skill learning. Nature 377:155-158. CrossRef Medline

Kilavik BE, Roux S, Ponce-Alvarez A, Confais J, Grün S, Riehle A (2009) 
Long-term modifications in motor cortical dynamics induced by intensive practice. J Neurosci 29:12653-12663. CrossRef Medline

Kleim JA, Hogg TM, VandenBerg PM, Cooper NR, Bruneau R, Remple M (2004) Cortical synaptogenesis and motor map reorganization occur during late, but not early, phase of motor skill learning. J Neurosci 24: 628-633. CrossRef Medline

Komiyama T, Sato TR, O'Connor DH, Zhang YX, Huber D, Hooks BM, Gabitto M, Svoboda K (2010) Learning-related fine-scale specificity imaged in motor cortex circuits of behaving mice. Nature 464:1182-1186. CrossRef Medline

Konaka K, Kondo J, Hirota N, Tamine K, Hori K, Ono T, Maeda Y, Sakoda S, Naritomi H (2010) Relationship between tongue pressure and dysphagia in stroke patients. Eur Neurol 64:101-107. CrossRef Medline

Lin LD, Murray GM, Sessle BJ (1993) The effect of bilateral cold block of the primate face primary somatosensory cortex on the performance of trained tongue-protrusion task and biting tasks. J Neurophysiol 70:985996. Medline

Lin LD, Murray GM, Sessle BJ (1994) Functional properties of single neurons in the primate face primary somatosensory cortex: I. Relations with trained orofacial motor behaviors. J Neurophysiol 71:2377-2390. Medline

Lowe AA (1980) The neural regulation of tongue movements. Prog Neurobiol 15:295-344. CrossRef Medline

Martin RE (2009) Neuroplasticity and swallowing. Dysphagia 24:218-229. CrossRef Medline

Maynard EM, Hatsopoulos NG, Ojakangas CL, Acuna BD, Sanes JN, Normann RA, Donoghue JP (1999) Neuronal interactions improve cortical population coding of movement direction. J Neurosci 19:8083-8093. Medline

Mistry S, Michou E, Rothwell J, Hamdy S (2012) Remote effects of intermittent theta burst stimulation of the human pharyngeal motor system. Eur J Neurosci 36:2493-2499. CrossRef Medline

Mitra PP, Pesaran B (1999) Analysis of dynamic brain imaging data. Biophys J 76:691-708. CrossRef Medline

Murdoch BE, Ng ML, Barwood CH (2012) Treatment of articulatory dysfunction in Parkinson's disease using repetitive transcranial magnetic stimulation. Eur J Neurol 19:340-347. CrossRef Medline

Murray GM, Sessle BJ (1992a) Functional properties of single neurons in the face primary motor cortex of the primate: I. Input and output features of tongue motor cortex. J Neurophysiol 67:747-758. Medline

Murray GM, Sessle BJ (1992b) Functional properties of single neurons in the face primary motor cortex of the primate: II. Relations with trained orofacial motor behavior. J Neurophysiol 67:759-774. Medline

Murray GM, Lin LD, Moustafa EM, Sessle BJ (1991) Effects of reversible inactivation by cooling of the primate face motor cortex on the performance of a trained tongue-protrusion task and a trained biting task. J Neurophysiol 65:511-530. Medline

Murthy VN, Fetz EE (1992) Coherent 25- to 35-Hz oscillations in the sensorimotor cortex of awake behaving monkeys. Proc Natl Acad Sci U S A 89:5670-5674. CrossRef Medline

Nuckolls AL, Worley C, Leto C, Zhang H, Morris JK, Stanford JA (2012) Tongue force and tongue motility are differently affected by unilateral vs bilateral nigrostriatal dopamine depletion in rats. Behav Brain Res 234: 343-348. CrossRef Medline

Nudo RJ, Milliken GW, Jenkins WM, Merzenich MM (1996) Usedependent alterations of movement representations in primary motor cortex of adult squirrel monkeys. J Neurosci 16:785-807. Medline

Pavlides C, Miyashita E, Asanuma H (1993) Projection from the sensory to the motor cortex is important in learning motor skills in the monkey. J Neurophysiol 70:733-741. Medline

Paz R, Vaadia E (2004) Learning-induced improvement in encoding and decoding of specific movement directions by neurons in the primary motor cortex. PLoS Biol 2:E45. CrossRef Medline

Paz R, Boraud T, Natan C, Bergman H, Vaadia E (2003) Preparatory activity in motor cortex reflects learning of local visuomotor skills. Nat Neurosci 6:882-890. CrossRef Medline

Richardson AG, Borghi T, Bizzi E (2012) Activity of the same motor cortex neurons during repeated experience with perturbed movement dynamics. J Neurophysiol 107:3144-3154. CrossRef Medline

Riehle A, Grün S, Diesmann M, Aertsen A (1997) Spike synchronization and rate modulation differentially involved in motor cortical function. Science 278:1950-1953. CrossRef Medline

Sakamoto K, Mushiake H, Saito N, Aihara K, Yano M, Tanji J (2008) Discharge synchrony during the transition of behavioral goal representations encoded by discharge rates of prefrontal neurons. Cereb Cortex 18:20362045. CrossRef Medline

Salinas E, Abbott LF (1995) Transfer of coded information from sensory to motor networks. J Neurosci 15:6461-6474. Medline

Salinas E, Romo R (1998) Conversion of sensory signals into motor commands in primary motor cortex. J Neurosci 18:499-511. Medline

Sessle BJ (2006) Mechanisms of oral somatosensory and motor functions and their clinical correlates. J Oral Rehabil 33:243-261. CrossRef Medline

Sessle BJ, Yao D, Nishiura H, Yoshino K, Lee JC, Martin RE, Murray GM (2005) Properties and plasticity of the primate somatosensory and motor cortex related to orofacial sensorimotor function. Clin Exp Pharmacol Physiol 32:109-114. CrossRef Medline

Sessle BJ, Adachi K, Avivi-Arber L, Lee J, Nishiura H, Yao D, Yoshino K (2007) Neuroplasticity of face primary motor cortex control of orofacial movements. Arch Oral Biol 52:334-337. CrossRef Medline

Shannon CE (1948) A mathematical theory of communication. Bell Sys Tech J 27:379-423. CrossRef

Song S, Miller KD, Abbott LF (2000) Competitive Hebbian learning through spike-timing-dependent synaptic plasticity. Nat Neurosci 3:919 926. CrossRef Medline

Song W, Kerr CC, Lytton WW, Francis JT (2013) Cortical plasticity induced by spike-triggered microstimulation in primate somatosensory cortex. PLoS One 8:e57453. CrossRef Medline

Svensson P, Romaniello A, Arendt-Nielsen L, Sessle BJ (2003) Plasticity in corticomotor control of the human tongue musculature induced by tongue-task training. Exp Brain Res 152:42-51. CrossRef Medline

Svensson P, Romaniello A, Wang K, Arendt-Nielsen L, Sessle BJ (2006) One hour of tongue-task training is associated with plasticity in corticomotor control of the human tongue musculature. Exp Brain Res 173:165-173. CrossRef Medline

Xu T, Yu X, Perlik AJ, Tobin WF, Zweig JA, Tennant K, Jones T, Zuo Y (2009) Rapid formation and selective stabilization of synapses for enduring motor memories. Nature 462:915-919. CrossRef Medline

Yang G, Pan F, Gan WB (2009) Stably maintained dendritic spines are associated with lifelong memories. Nature 462:920-924. CrossRef Medline

Yao D, Yamamura K, Narita N, Martin RE, Murray GM, Sessle BJ (2002) Neuronal activity patterns in primate primary motor cortex related to trained or semiautomatic jaw and tongue movements. J Neurophysiol 87:2531-2541. Medline

Yoshino K, Kawagishi S, Takatsuki Y, Amano N (2000) Functional properties of the primary motor cortex and ventral premotor cortex in the monkey during a visually guided jaw-movement task with a delay period. Brain Res 852:414-423. CrossRef Medline 